\title{
Aflibercept exhibits VEGF binding stoichiometry distinct from bevacizumab and does not support formation of immune-like complexes
}

\author{
Douglas A. MacDonald ${ }^{1} \cdot$ Joel Martin $^{1} \cdot$ Kathir K. Muthusamy $^{1} \cdot$ Jiann-Kae Luo $^{1}$ • \\ Erica Pyles $^{1} \cdot$ Ashique Rafique $^{1} \cdot$ Tammy Huang $^{1} \cdot$ Terra Potocky $^{1}$. \\ Yang Liu ${ }^{1} \cdot$ Jingtai Cao $^{1} \cdot$ Françoise Bono $^{2} \cdot$ Nathalie Delesque $^{2} \cdot$ Pierre Savi $^{2}$. \\ John Francis ${ }^{3}$ - Ali Amirkhosravi ${ }^{3}$. Todd Meyer ${ }^{3}$ - Carmelo Romano ${ }^{1}$. \\ Meredith Glinka $^{1} \cdot$ George D. Yancopoulos $^{1} \cdot$ Neil Stahl $^{1} \cdot$ Stanley J. Wiegand ${ }^{1}$. \\ Nicholas Papadopoulos ${ }^{1}$
}

Received: 18 December 2015/Accepted: 13 May 2016/Published online: 27 May 2016

(C) The Author(s) 2016. This article is published with open access at Springerlink.com

\begin{abstract}
Anti-vascular endothelial growth factor (VEGF) therapies have improved clinical outcomes for patients with cancers and retinal vascular diseases. Three antiVEGF agents, pegaptanib, ranibizumab, and aflibercept, are approved for ophthalmic indications, while bevacizumab is approved to treat colorectal, lung, and renal cancers, but is also used off-label to treat ocular vascular diseases. The efficacy of bevacizumab relative to ranibizumab in treating neovascular age-related macular degeneration has been assessed in several trials. However, questions persist regarding its safety, as bevacizumab can form large complexes with dimeric $\mathrm{VEGF}_{165}$, resulting in multimerization of the $\mathrm{Fc}$ domain and platelet activation. Here, we compare binding stoichiometry, $F c \gamma$ receptor affinity, platelet activation, and binding to epithelial and endothelial cells in vitro for bevacizumab and aflibercept, in the absence or presence of VEGF. In contrast to bevacizumab, aflibercept forms a homogenous 1:1 complex with
\end{abstract}

Douglas A. MacDonald and Joel Martin have contributed equally to this work.

Electronic supplementary material The online version of this article (doi:10.1007/s10456-016-9515-8) contains supplementary material, which is available to authorized users.

Nicholas Papadopoulos

nicholas.papadopoulos@ regeneron.com

1 Regeneron Pharmaceuticals Inc., 777 Old Saw Mill River Road, Tarrytown, NY 10591, USA

2 Sanofi, Toulouse, France

3 Center for Thrombosis Research, Florida Hospital, Orlando, FL, USA each VEGF dimer. Unlike multimeric bevacizumab:VEGF complexes, the monomeric aflibercept:VEGF complex does not exhibit increased affinity for low-affinity $\mathrm{Fc} \gamma$ receptors, does not activate platelets, nor does it bind to the surface of epithelial or endothelial cells to a greater degree than unbound aflibercept or control Fc. The latter finding reflects the fact that aflibercept binds VEGF in a unique manner, distinct from antibodies not only blocking the amino acids necessary for VEGFR1/R2 binding but also occluding the heparin-binding site on $\mathrm{VEGF}_{165}$.

Keywords VEGF · Bevacizumab · Aflibercept · Immune complexes

\section{Introduction}

Angiogenesis, the growth of new blood vessels from preexisting vasculature, is a highly orchestrated process that is critical for proper embryonic and postnatal vascular development [1]. Abnormal or pathological angiogenesis is a hallmark of cancer and several retinal diseases where the upregulation of proangiogenic factors, such as vascular endothelial growth factor (VEGF) and placental growth factor (PlGF), leads to increases in endothelial proliferation, changes in vasculature morphology, and increased vascular permeability [2, 3]. In particular, blockade of VEGF has shown clinical utility in the oncology setting as well as several retinal vascular diseases characterized by abnormal angiogenesis and/or vascular permeability, such as the "wet" form of age-related macular degeneration (AMD), the leading cause of blindness in the elderly [4, 5]. The formation of new blood vessels and vascular leakage 
in wet AMD leads to macular edema, thickening of the retina, and loss of vision. Elevated levels of VEGF have been found in the vitreous fluid and retinal vasculature of patients with AMD [6]. Blocking VEGF activity has also become the therapy of choice for treating diabetic macular edema (DME), retinal vein occlusions, and other ocular diseases where abnormal angiogenesis is the underlying etiology [7-10].

Several anti-VEGF therapies have been approved for use in neovascular or "wet" AMD. Pegaptanib, an oligonucleotide aptamer that binds the heparin-binding domain of $\mathrm{VEGF}_{165}$, was the first anti-VEGF therapy that showed some benefit in treating wet AMD, although most patients still experienced visual decline [11]. The introduction of ranibizumab, an affinity-matured, humanized monoclonal antibody fragment (Fab), represented a major advance in treating wet AMD patients since it was not only able to stabilize but in many cases improve visual acuity [12]. However, prior to regulatory approval of ranibizumab, ophthalmologists began using bevacizumab, a humanized monoclonal antibody to VEGF already approved for metastatic colorectal cancer, to treat wet AMD. Like ranibizumab, bevacizumab binds to all isoforms of VEGF-A, but is aliquoted and repackaged for offlabel use in ophthalmological indications [13]. Several, small, non-randomized studies evaluated bevacizumab as a potential treatment option in the treatment for wet AMD and thus began the ongoing debate on the merits of utilizing bevacizumab for the treatment for diseases affecting the ocular vasculature [14]. More recently, in a large $(n=1208)$, prospective, randomized comparison of agerelated macular degeneration treatments trial (CATT), comparison of the same regimens of ranibizumab or bevacizumab demonstrated similar improvements for the primary end point of visual acuity at 1 year [15]. However, somewhat higher rates of systemic serious adverse events (SAEs) were observed in patients treated with bevacizumab compared to ranibizumab. Curiously, the excess in systemic SAEs observed in bevacizumab-treated patients in the CATT trial did not correspond to adverse cardiovascular events, such as hypertension and arteriothrombolic events (ATEs), previously known to be caused by systemic VEGF inhibition in oncology trials that employed much higher, intravenous doses of bevacizumab. Rather, patients treated intravitreally with low-dose bevacizumab exhibited increases in SAEs affecting other organ systems, particularly gastrointestinal disorders. While two additional, but smaller trials (IVAN; $n=610$, MANTA; $n=321$ ) individually showed no statistically significant differences in systemic SAEs between ranibizumab and bevacizumab [16, 17], a recent meta-analysis $(n=3665)$ comprising the above studies as well as six additional trials also found a higher incidence of gastrointestinal disorders in patients treated with intravitreal bevacizumab compared to ranibizumab, with no differences in other systemic SAEs [18]. In comparing the safety profile of ranibizumab to bevacizumab when treating DME, the recent Protocol T trial showed no differences in the rates of serious adverse events among all three anti-VEGF treatments (aflibercept, bevacizumab, ranibizumab), though visual acuity gains with aflibercept were significantly greater than with ranibizumab or bevacizumab in the overall population, and these differences were especially evident in patients with poor vision at the start of treatment [19].

Although mechanisms underlying the potentially higher rate of systemic SAEs not typically associated with antiVEGF activity in patients receiving intravitreal bevacizumab remains unknown, a number of investigators have pointed out several fundamental differences between ranibizumab and bevacizumab. First, ranibizumab is a Fab fragment and is significantly smaller in size than a fulllength antibody. This was advantageous for the development for intravitreal injection as the smaller size of ranibizumab was expected to enhance diffusion from the vitreous into the retina and choroid [20]. VEGF and closely related molecules are ligands for a family of related receptor tyrosine kinases (VEGFRs), and as such exist naturally as dimers. Since ranibizumab is a Fab fragment, two molecules of ranibizumab are bound by each VEGF dimer. In contrast, bevacizumab is an IgG comprising two Fabs as well as an Fc domain. Due to its bivalent nature, a single bevacizumab molecule can bind both active sites in a single VEGF dimer. Interestingly, it has also been reported that bevacizumab has the capacity to form large multimeric complexes with VEGF [21, 22]. Second, though derived from bevacizumab, ranibizumab has been affinity-matured with a reported affinity enhancement of 10- to 100-fold relative to the Fab, which is associated with a similarly enhanced activity of ranibizumab in cell-based assays, compared to the Fab fragment of bevacizumab $[23,24]$. However, the bivalent nature of the full-length bevacizumab antibody contributes substantially to its ability to bind and neutralize VEGF. Specifically, avidity interactions of bevacizumab with its dimeric VEGF target significantly increase binding affinity and potency of the bivalent antibody relative to the monovalent antigenbinding fragment [25]. Lastly, ranibizumab does not contain a fragment crystallizable $(\mathrm{Fc})$ region, unlike full-length antibodies. While the $\mathrm{Fc}$ moiety is useful to increase circulatory half-life when an antibody is given systemically, via its interactions with the neonatal receptor, the $\mathrm{Fc}$ region can also promote effector function if the antibody is multimerized upon binding to its target. In the absence of this multimerization, the $\mathrm{Fc}$ domain of therapeutic antibodies rarely occupies $\mathrm{Fc} \gamma$ receptors due to the constant competition with high levels of endogenous IgG (5-15 g/L) [26]. 
Meyer et al. [22] have shown that bevacizumab and equimolar amounts of $\mathrm{VEGF}_{165}$ can form immune-like complexes, which in the presence of heparin can engage the Fc $\gamma$ RIIa receptor on thrombocytes leading to platelet activation. Other studies have also reported differences in the activities of ranibizumab and bevacizumab that appear to be unrelated to VEGF neutralization per se. For example, bevacizumab exhibits enhanced binding to and accumulation in retinal pigment epithelium (RPE) cells in vitro, relative to ranibizumab [27].

Aflibercept is a novel soluble decoy receptor consisting of an all-human amino acid sequence comprising the second Ig domain of human VEGFR1 and the third Ig domain of human VEGFR2 expressed as an inline fusion with the constant region $(\mathrm{Fc})$ of human IgG1 [28]. Like bevacizumab and ranibizumab, aflibercept binds all forms of VEGF-A (VEGF) but in addition binds PIGF and VEGF-B [25]. Aflibercept was recently approved for the treatment for wet AMD based on the VIEW studies [29]. These trials demonstrated equivalent improvements in visual acuity at 1 year between patients treated monthly with ranibizumab and those treated with aflibercept every other month following three initial monthly loading doses. Each aflibercept molecule, like bevacizumab, contains two, independent VEGF binding arms held together via the Fc moiety. Upon binding VEGF dimers, aflibercept could in theory form large, multimeric immune-like complexes similar to those previously described for bevacizumab, which in turn could trigger processes mediated by low-affinity Fc receptors.

In the present study, we compare the binding stoichiometries of bevacizumab and aflibercept to $\mathrm{VEGF}_{165}$, over a range of relative molar concentrations, and also assessed the binding affinities of bevacizumab and aflibercept to $\mathrm{VEGF}_{121}, \mathrm{VEGF}_{165}$, and $\mathrm{Fc} \gamma$ receptors, alone or when complexed with VEGF. The ability of bevacizumab:VEGF and aflibercept:VEGF complexes to activate human platelets in vitro, and the propensity of both bevacizumab and aflibercept to bind to cultured human retinal epithelial (ARPE-19) and human umbilical vein endothelial cells (HUVEC) in the presence and absence of VEGF $_{165}$ and VEGF $_{121}$ also were assessed. The results of these experiments confirm that bevacizumab can form large multimeric complexes with VEGF, when both antibody and ligand are present in roughly (within tenfold) equimolar concentrations. In contrast, aflibercept forms a homogenous 1:1 complex with VEGFs over all molar ratios tested. Moreover, in contrast to the large and heterogenous bevacizumab:VEGF 165 complexes, these discrete aflibercept: $V_{E G F}{ }_{165}$ complexes do not activate platelets in the presence of heparin. Finally, aflibercept does not bind to the surface of HUVEC or ARPE-19 cells to an appreciably greater degree than the control, human $\mathrm{Fc}(\mathrm{hFc})$, in the presence or absence of VEGFs. In contrast, binding of bevacizumab to the surface of these cells was greatly enhanced in the presence of exogenous or endogenous $\mathrm{VEGF}_{165}$, but not $\mathrm{VEGF}_{121}$. This finding suggested that the cell surface binding of bevacizumab: VEGF $_{165}$ complexes was mediated by the heparin and/or neuropilin-1 (NRP1)binding domains of this VEGF isoform. This was confirmed by subsequent surface plasmon resonance (Biacore) experiments, which showed that bevacizumab:VEGF 165 complexes, but not aflibercept:VEGF ${ }_{165}$ complexes, were readily bound by surface-captured NRP1 or heparin. In conclusion, under certain conditions, bevacizumab can form large, multimeric immune-like complexes that exhibit enhanced binding not only to a range of $\mathrm{Fc} \gamma$ receptors, but also, when complexed with $\mathrm{VEGF}_{165}$, to heparin and neuropilin present on the surfaces of cells. In contrast, aflibercept exclusively forms a 1:1 complex with VEGF dimers, which does not appreciably increase binding to low-affinity $\mathrm{Fc}$ receptors, heparin, or neuropilin-compared to unbound aflibercept or control, monomeric IgGs. The fundamental difference between bevacizumab and aflibercept behavior appears to be attributable to the unique way in which the aflibercept encompasses or "Traps" a single, VEGF dimer, not only blocking the amino acids necessary for VEGFR1/R2 binding but also occluding the heparin-binding site on VEGF as well.

\section{Results}

\section{In contrast to bevacizumab, aflibercept forms a 1:1 complex with VEGF}

Multiple-angled laser light scattering (MALLS) coupled to size exclusion chromatography (SEC) was used to calculate the stoichiometry of bevacizumab: $\mathrm{VEGF}_{165}$ and aflibercept:VEGF 165 complexes. VEGF $_{165}$ was mixed with either bevacizumab or aflibercept in solution at molar ratios of inhibitor to ligand of between 5:1 and 1:5. Bevacizumab was found to form a heterogeneous mixture of multimeric complexes in the presence of $\mathrm{VEGF}_{165}$, with molar masses ranging from $\sim 330$ to $700 \mathrm{kDa}$ (Fig. 1a). In contrast, aflibercept at a 1:5 molar ratio showed two discrete peaks (Fig. 1b), as expected based on previous results [21]. The earlier eluting peak, with an apparent molar mass of $157 \mathrm{kDa}$, corresponded to a 1:1 complex between aflibercept $(\sim 115 \mathrm{kDa})$ and $\mathrm{VEGF}_{165}$ ( $\sim 40 \mathrm{kDa})$. The latter eluting peak corresponded to the expected excess of free $\mathrm{VEGF}_{165}$ dimer (based on the average molar mass of the peak and comparison with the elution times from $\mathrm{VEGF}_{165}$ injections). Analysis of a preformed aflibercept:VEGF 165 complex at a 5:1 molar 
Fig. 1 Aflibercept forms 1:1 complexes with VEGF $_{165}$. The molar masses of aflibercept:VEGF 165 and bevacizumab: VEGF $_{165}$ complexes were analyzed by multi-angle laser light scattering detection coupled to SEC. The differential refractive index (right $y$ axis) and the measured molar mass (left $y$ axis) of peaks are indicated as a function of elution volume for each sample. The experimentally determined molar masses are indicated by horizontal lines. Cartoons of free $\mathrm{VEGF}_{165}$ and complexes of aflibercept or bevacizumab bound to $\mathrm{VEGF}_{165}$ are shown. Complexes of VEGF $_{165}$ with bevacizumab (a) or aflibercept (b) at various molar ratios were incubated for $12 \mathrm{~h}$ at ambient temperature. Following incubation, the samples were kept at $4{ }^{\circ} \mathrm{C}$ in the autosampler prior to injection

( 100-200 $\mu \mathrm{g}$ per sample) onto a Superose 12 column preequilibrated in $10 \mathrm{mM}$ phosphate containing $500 \mathrm{mM}$ $\mathrm{NaCl}$ buffer ( $\mathrm{pH} 7.0$ ) with a flow rate of $0.3 \mathrm{~mL} / \mathrm{min}$. Chromatograms of VEGF $_{165}$ and bevacizumab (a) or aflibercept (b) are superimposed to indicate the elution profiles of the unbound proteins. The 1:1 molar ratio complexes yielded similar elution profiles and are not shown for the purposes of clarity

\section{Chromatograms of bevacizumab and aflibercept in the presence and absence of $\mathrm{VEGF}_{165}$}
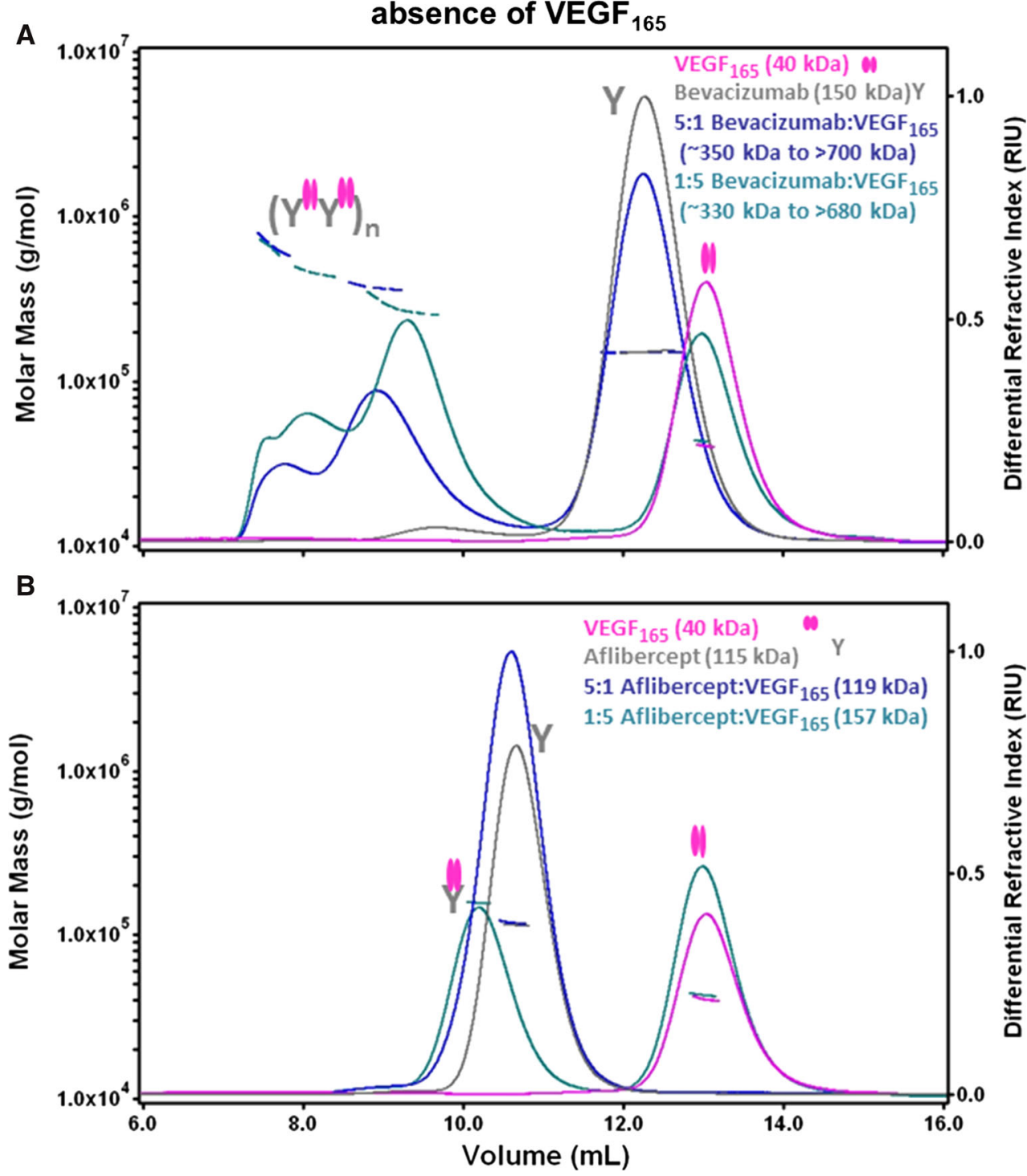

ratio showed a single peak of $119 \mathrm{kDa}$ (Fig. 1b), which is attributed to incomplete separation between the $1: 1$ aflibercept:VEGF 165 complex $(\sim 157 \mathrm{kDa})$ and the excess free aflibercept $(\sim 115 \mathrm{kDa})$.

SEC-MALLS analysis was also used to estimate the binding stoichiometry and molar mass of the complexes formed between bevacizumab or aflibercept and PlGF-2 (Figure S1). No complex formation was observed between bevacizumab and PlGF-2 (Figure S1A). The aflibercept:PlGF-2 complex demonstrated a very similar stoichiometry to the aflibercept:VEGF 165 complex, with a single major homogenous peak (molar mass of $150 \mathrm{kDa}$ ) corresponding to a 1:1 complex between aflibercept and PlGF-2 ( $42 \mathrm{kDa})$ and a minor peak corresponding to an excess of free PlGF-2 dimer (Figure S1B).

\section{Aflibercept's binding half-life to Fc $\gamma$ receptors does not change in the presence of VEGF}

Surface plasmon resonance was used to determine the dissociation rate constants $\left(k_{\mathrm{d}}\right)$ of bevacizumab and aflibercept to the family of human $F c \gamma$ receptors in the presence or absence of $\operatorname{VEGF}_{165}$ or $\operatorname{VEGF}_{121}$ (Table 1). Equilibrium binding constants $\left(K_{\mathrm{D}}=k_{\mathrm{d}} / k_{\mathrm{a}}\right)$ were not calculated since the heterogenous nature of the bevacizumab:VEGF complex did not allow accurate molar concentrations to be utilized and thus association rate constants $\left(k_{\mathrm{a}}\right)$, which are dependent on concentration, could not be determined. Bevacizumab and aflibercept, in the absence of VEGF, exhibited the expected rapid dissociation rate constant $\left(k_{\mathrm{d}}\right)$ from low-affinity Fc receptors, with 
Table 1 In vitro binding affinity of bevacizumab and aflibercept for Fc $\gamma$ receptors in the presence and absence of VEGF $_{121}$ and VEGF VE5 $_{165}$ determined by SPR (Biacore)

\begin{tabular}{|c|c|c|c|c|c|c|c|c|c|c|}
\hline \multirow{2}{*}{$\begin{array}{l}\text { VEGF inhibitors } \\
(1 \mu \mathrm{M})\end{array}$} & \multirow{2}{*}{$\begin{array}{l}\text { Ligand injected } \\
(1 \mu \mathrm{M})\end{array}$} & \multicolumn{3}{|l|}{$\mathrm{Fc} \gamma \mathrm{RI}$} & \multicolumn{3}{|l|}{$\mathrm{Fc} \mathrm{RIII}^{\mathrm{b}}$} & \multicolumn{3}{|l|}{ Fc $\gamma$ RIIb } \\
\hline & & $k_{\mathrm{d}}(1 / \mathrm{s})$ & $\begin{array}{l}t_{1 / 2} \\
(\mathrm{~s})\end{array}$ & $\begin{array}{l}t_{1 / 2} \text { Fold } \\
\text { changes }^{\mathrm{a}}\end{array}$ & $k_{\mathrm{d}}(1 / \mathrm{s})$ & $\begin{array}{l}t_{1 / 2} \\
(\mathrm{~s})\end{array}$ & $\begin{array}{l}t_{1 / 2} \text { Fold } \\
\text { changes }^{\mathrm{a}}\end{array}$ & $k_{\mathrm{d}}(1 / \mathrm{s})$ & $\begin{array}{l}t_{1 / 2} \\
(\mathrm{~s})\end{array}$ & $\begin{array}{l}t_{1 / 2} \text { fold } \\
\text { changes }^{\mathrm{a}}\end{array}$ \\
\hline \multirow[t]{3}{*}{ Bevacizumab } & - & $7.49 \mathrm{E}-04$ & 925 & 1 & $1.11 \mathrm{E}-01$ & 6 & 1 & $1.79 \mathrm{E}-01$ & 4 & 1 \\
\hline & $\mathrm{VEGF}_{165}$ & $2.41 \mathrm{E}-04$ & 2874 & 3 & $1.02 \mathrm{E}-03$ & 681 & 114 & $9.80 \mathrm{E}-04$ & 707 & 177 \\
\hline & $\mathrm{VEGF}_{121}$ & $2.03 \mathrm{E}-04$ & 3419 & 4 & $1.42 \mathrm{E}-03$ & 487 & 81 & $1.82 \mathrm{E}-03$ & 380 & 95 \\
\hline \multirow[t]{3}{*}{ Aflibercept } & - & $7.21 \mathrm{E}-04$ & 961 & 1 & $2.24 \mathrm{E}-01$ & 3 & 1 & $2.55 \mathrm{E}-01$ & 3 & 1 \\
\hline & VEGF $_{165}$ & $6.17 \mathrm{E}-04$ & 1123 & 1 & $2.05 \mathrm{E}-01$ & 3 & 1 & $1.74 \mathrm{E}-01$ & 4 & 1 \\
\hline & $\mathrm{VEGF}_{121}$ & $6.83 \mathrm{E}-04$ & 1015 & 1 & $1.86 \mathrm{E}-01$ & 4 & 1 & $2.05 \mathrm{E}-01$ & 3 & 1 \\
\hline \multirow{2}{*}{$\begin{array}{l}\text { VEGF inhibitors } \\
(1 \mu \mathrm{M})\end{array}$} & \multirow{2}{*}{$\begin{array}{l}\text { Ligand injected } \\
(1 \mu \mathrm{M})\end{array}$} & \multicolumn{3}{|c|}{ Fc $\gamma$ RIIIa $(176 \mathrm{~V})^{\mathrm{c}}$} & \multicolumn{3}{|c|}{ Fc $\gamma$ RIIIa $(176 \mathrm{~F})^{\mathrm{d}}$} & \multicolumn{3}{|l|}{ Fc $\gamma$ RIIIb } \\
\hline & & $k_{\mathrm{d}}(1 / \mathrm{s})$ & $\begin{array}{l}t_{1 / 2} \\
(\mathrm{~s})\end{array}$ & $\begin{array}{l}t_{1 / 2} \text { fold } \\
\text { changes }^{\mathrm{a}}\end{array}$ & $k_{\mathrm{d}}(1 / \mathrm{s})$ & $\begin{array}{l}t_{1 / 2} \\
(\mathrm{~s})\end{array}$ & $\begin{array}{l}t_{1 / 2} \text { fold } \\
\text { changes }^{\mathrm{a}}\end{array}$ & $k_{\mathrm{d}}(1 / \mathrm{s})$ & $\begin{array}{l}t_{1 / 2} \\
(\mathrm{~s})\end{array}$ & $\begin{array}{l}t_{1 / 2} \text { fold } \\
\text { changes }^{\mathrm{a}}\end{array}$ \\
\hline \multirow[t]{3}{*}{ Bevacizumab } & - & $8.03 \mathrm{E}-03$ & 86 & 1 & $6.26 \mathrm{E}-02$ & 11 & 1 & $1.96 \mathrm{E}-01$ & 4 & 1 \\
\hline & VEGF $_{165}$ & $7.78 \mathrm{E}-04$ & 891 & 10 & $1.30 \mathrm{E}-03$ & 533 & 48 & $1.50 \mathrm{E}-03$ & 463 & 116 \\
\hline & $\mathrm{VEGF}_{121}$ & $9.09 \mathrm{E}-04$ & 762 & 9 & $1.83 \mathrm{E}-03$ & 378 & 34 & $2.61 \mathrm{E}-03$ & 265 & 66 \\
\hline \multirow[t]{3}{*}{ Aflibercept } & - & $7.62 \mathrm{E}-03$ & 91 & 1 & $4.89 \mathrm{E}-02$ & 14 & 1 & $1.71 \mathrm{E}-01$ & 4 & 1 \\
\hline & VEGF $_{165}$ & $6.14 \mathrm{E}-03$ & 113 & 1 & $3.92 \mathrm{E}-02$ & 18 & 1 & $1.64 \mathrm{E}-01$ & 4 & 1 \\
\hline & VEGF $_{121}$ & $5.73 \mathrm{E}-03$ & 121 & 1 & $3.61 \mathrm{E}-02$ & 19 & 1 & $1.42 \mathrm{E}-01$ & 5 & 1 \\
\hline
\end{tabular}

${ }^{\mathrm{a}}$ Fold $=t_{1 / 2}$ (ligand + VEGF inhibitor complex)/ $t_{1 / 2}$ (VEGF inhibitor alone)

${ }^{b}$ Fc $\gamma$ RIIa allele studied was 131R

${ }^{c}$ Fc $\gamma$ RIIIa allele studied was $176 \mathrm{~V}$

${ }^{\mathrm{d}}$ Fc $\gamma$ RIIIa allele studied was $176 \mathrm{~F}$

$t_{1 / 2}$ values typical for unbound endogenous $\operatorname{IgG} 1$ and recombinant molecules containing IgG1-Fc $\left(K_{\mathrm{D}} \approx 1-10 \mu \mathrm{M}\right)$ [30]. However, when bevacizumab was pre-incubated in a 1:1 molar ratio with $\mathrm{VEGF}_{165}$ or VEGF $_{121}$, the resulting complexes exhibited longer $t_{1 / 2}$ values (slower dissociation rate constants) when bound to the low-affinity Fc $\gamma$ receptors Fc $\gamma$ RIIa, Fc $\gamma$ RIIb, Fc $\gamma$ RIIIa (176F), Fc $\gamma$ RIIIa (176 V), and Fc $\gamma$ RIIIb compared to bevacizumab alone. This increase in binding half-life ranged from a ninefold increase when the bevacizumab:VEGF complex was flowed over Fc $\gamma$ RIIIa $(176 \mathrm{~V})$ to a 177 -fold increase in $t_{1 / 2}$ when flowed over Fc $\gamma$ RIIb. In contrast, aflibercept with or without VEGF present exhibited no change in $t_{1 / 2}$ values when bound to $\mathrm{Fc} \gamma$ receptors. Representative sensorgrams of bevacizumab and aflibercept binding to $\mathrm{Fc} \gamma$ receptors are shown in Figures S2, S3, S4.

\section{Aflibercept:VEGF ${ }_{165}$ complexes do not activate platelets}

Previous studies have demonstrated that, in the presence of heparin, bevacizumab: $\mathrm{VEGF}_{165}$ complexes can activate human platelets via Fc $\gamma$ RIIa [22]. The potential for
aflibercept-VEGF ${ }_{165}$ complexes to induce Fc $\gamma$ RIIa-dependent platelet activation was tested using light aggregometry. Preformed complexes of aflibercept and $\mathrm{VEGF}_{165}$ at equal molar ratios in the presence of heparin failed to induce aggregation of human platelets (Fig. 2a). In contrast, preformed complexes of bevacizumab and VEGF $_{165}$ at equal molar ratios in the presence of heparin caused marked aggregation of platelets over a concentration range of 100-400 nM (Fig. 2b). However, increasing the molar excess of bevacizumab ( $\geq$ fourfold relative to $\mathrm{VEGF}_{165}$ ) results in a loss of platelet activation (data not shown) Bevacizumab:VEGF complexes below $100 \mathrm{nM}$ did not activate platelets. Platelet activation was not detected at concentrations below $100 \mathrm{nM}$ of bevacizumab:VEGF 165 complex.

Platelet activation was also tested using a serotonin release assay. The combination of aflibercept and $\mathrm{VEGF}_{165}$ at equal molar ratios (500 $\mathrm{nM}$ each) in the presence of heparin was unable to stimulate serotonin release from platelets (Fig. 2c). However, the presence of bevacizumab and $\mathrm{VEGF}_{165}$ at an equal molar ratio of $500 \mathrm{nM}$ each in the presence of heparin induced up to $80 \%$ release of serotonin from platelets (Fig. 2d), consistent with findings from the light aggregometry assays. 

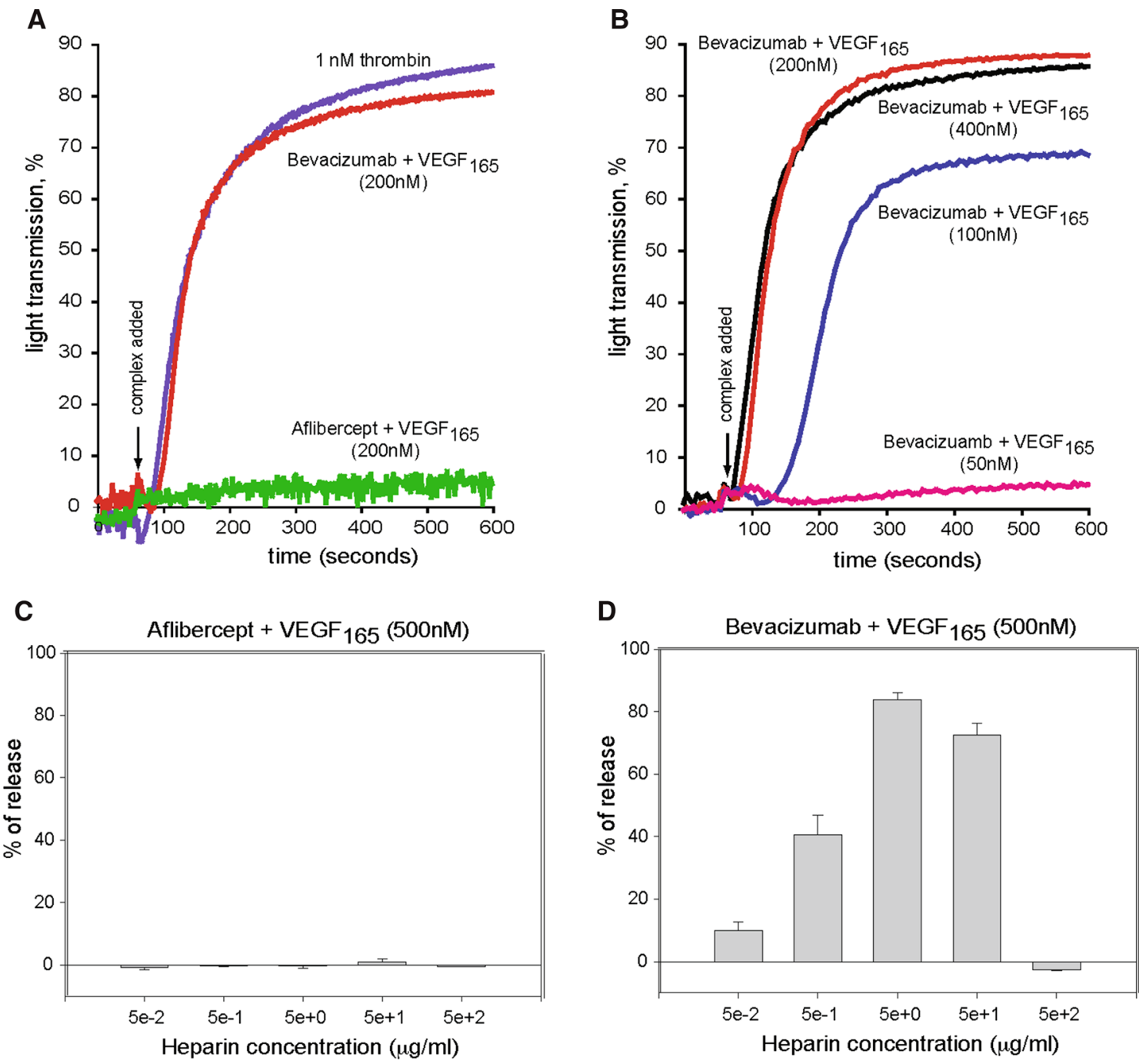

Fig. 2 Aflibercept:VEGF 165 complexes do not activate platelets in vitro. a Preformed equal molar $(200 \mathrm{nM})$ aflibercept:VEGF ${ }_{165}$ or bevacizumab: $\mathrm{VEGF}_{165}$ complexes were added to primed $(1 \mu \mathrm{M}$ epinephrine), washed platelets containing $200 \mathrm{nM} U F H$ unfractionated heparin and percent light transmittance monitored at $600 \mathrm{~nm}$. Thrombin ( $1 \mathrm{nM}$, Chrono-PAR) acted as the positive control. b A range (400-50 nM) of preformed equal molar bevacizumab:VEGF 165 complexes were added to primed, washed platelets containing $U F H$

\section{Aflibercept:VEGF 165 complexes do not induce thrombocytopenia or thrombosis in FcyRIIa transgenic mice}

Injection of preformed (1:1 molar) bevacizumab:VEGF 165 complexes along with unfractionated heparin into transgenic mice expressing human Fc $\gamma$ RIIa has been reported to cause severe thrombocytopenia and occlusive thrombosis in alveolar capillaries [22]. We sought to determine whether preformed aflibercept:VEGF 165 complexes in the presence of unfractionated heparin could trigger a similar set of sequelae in human Fc $\gamma$ RIIa transgenic mice. Animals receiving aflibercept: $\mathrm{VEGF}_{165}$ complexes (1:1 molar ratio)

unfractionated heparin and percent light transmittance monitored. A similar experiment using aflibercept: $\mathrm{VEGF}_{165}$ complexes did not activate platelets (data not shown), and thus, only data for the $200 \mathrm{nM}$ complex (a) are shown. Serotonin release was measured from platelets stimulated in the presence of a range of concentrations $(0.1,0.2,0.5$ or $1.0 \mu \mathrm{M})$ of UFH with aflibercept:VEGF ${ }_{165}$ complex (c) or bevacizumab:VEGF 165 complex (d). Inhibitor:ligand complex concentration was $500 \mathrm{nM}$

did not exhibit these symptoms $(n=10)$. Platelet counts 10 min following immune complex injection demonstrated thrombocytopenia in animals receiving bevacizumab:VEGF 165 but not aflibercept:VEGF ${ }_{165}$ complexes (Fig. 3a). Specifically, mice injected with phosphate-buffered saline (PBS; $n=5$ ) had baseline platelet counts of $(1173 \pm 179$; mean $\pm \mathrm{SD})$, whereas animals receiving bevacizumab $+\mathrm{VEGF}_{165}$ had mean platelet counts of $331 \pm 217$ (with heparin; $P<0.001$ ) and $725 \pm 303$ (without heparin; $P<0.003$ ). Mice receiving aflibercept + VEGF $_{165}$ had mean platelet counts of $966 \pm 168$ (with heparin) and $878 \pm 250$ (without heparin), which were not statistically different from baseline (PBS) animal 

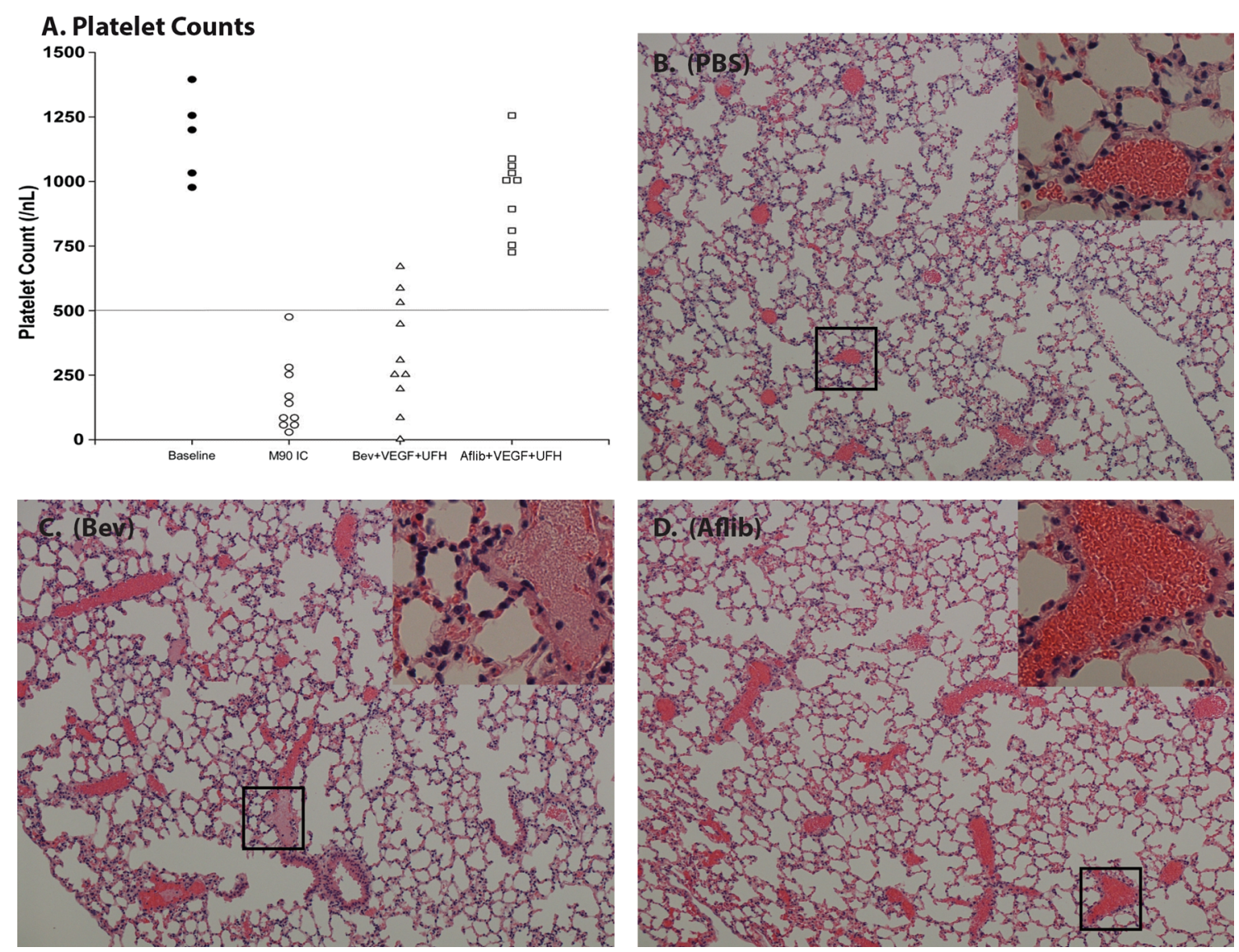

Fig. 3 Aflibercept $+\mathrm{VEGF}_{165}+$ unfractionated heparin (UFC) complexes do not activate platelets in vivo. B6;SJL-Tg (Fc $\gamma$ RIIa)11Mkz (FCGR2A) mice were injected with PBS $(n=5)$ or preformed immune complexes ( $n=10$ per group) via the tail vein. Ten minutes after reagent injection, mice were anesthetized, blood was collected by cardiac puncture, and platelet counts were measured using an automated cell counter. Following blood draws, animals were killed and lungs were dissected, rinsed, and embedded in paraffin. Paraffin blocks were sliced, and cut sections $(2 \mu \mathrm{m}$ thick)

were deparaffinized, rehydrated, and stained. Shown are platelet counts per individual Fc $\gamma$ RIIa animal by treatment group (a) along with representative H\&E microscopy sections for PBS (b) bevacizumab $(\mathrm{Bev})+\mathrm{VEGF}_{165}+$ heparin (c) and aflibercept + VEGF $_{165}+$ heparin (d). The horizontal line in (a) represents approximately $60 \%$ of reduction from baseline mean platelet count. Microscopy images were captured at $\times 200$ magnification. Insets represent $\times 700$ magnification

counts. Mouse antihuman CD-40 ligand immune complexes [22] served as a positive control and induced severe thrombocytopenia in Fc $\gamma$ RIIa transgenic mice with mean platelet counts of $163 \pm 137(P<0.001)$.

Consistent with the thrombocytopenia, mice injected with bevacizumab:VEGF 165 complexes developed abundant occlusive thrombi in the pulmonary vasculature (Fig. 3c). In contrast, mice injected with aflibercept:VEGF ${ }_{165}$ complexes failed to develop microvascular thrombosis (Fig. 3d).

\section{Aflibercept exhibits no significant cell surface binding to ARPE-19 cells or HUVEC}

Cell surface binding of aflibercept and bevacizumab alone or in complex with VEGF was tested using ARPE-19 (Fig. 4a) and HUVEC (Fig. 4b). Binding studies were

conducted for both inhibitors with no ligand present or following pre-incubation with $\mathrm{VEGF}_{121}$ or $\mathrm{VEGF}_{165}$. Binding to ARPE-19 cells was not observed for bevacizumab or aflibercept in complex with $\mathrm{VEGF}_{121}$ or in the absence of ligand (Fig. 4a, row 1, 3), but significant ARPE19 cell surface binding was observed for bevacizumab: $\mathrm{VEGF}_{165}$ complexes. Binding was not observed for the aflibercept:VEGF 165 complex (Fig. 4a, row 2). Similarly, binding to HUVEC was not observed for aflibercept or bevacizumab in complex with $\mathrm{VEGF}_{121}$ or in the absence of ligand (Fig. 4b, row 1, 3). However, significant HUVEC cell surface binding was observed for bevacizumab: $\mathrm{VEGF}_{165}$ complexes, and only very low levels of surface binding were observed for aflibercept:VEGF ${ }_{165}$ complexes (Fig. 4B, row 2). Complexes binding to the cell surface of both ARPE-19 and HUVEC were found to be dependent on the molar ratio of the 
Fig. 4 Aflibercept does not exhibit significant cell surface binding to ARPE-19 and HUVEC. Cell surface binding of aflibercept and bevacizumab was evaluated using ARPE-19 (a) and HUVEC (b). Cells were pre-seeded on collagen-coated 96-well plates. ARPE-19 cells were incubated with $5 \mathrm{nM}$ bevacizumab or aflibercept alone or in the presence of $10 \mathrm{nM}$ VEGF $_{165}$ or $10 \mathrm{nM}$ VEGF $_{121}$ at $37{ }^{\circ} \mathrm{C}$ for $1 \mathrm{~h}$. HUVEC were incubated with $15 \mathrm{nM}$ bevacizumab or aflibercept alone or in the presence of $10 \mathrm{nM} \mathrm{VEGF}_{165}$ or $10 \mathrm{nM} \operatorname{VEGF}_{121}$ at $37^{\circ} \mathrm{C}$ for

$1 \mathrm{~h}$. Surface-bound inhibitor was detected by incubation with A488-anti-hIgG (Fc-specific) at $4{ }^{\circ} \mathrm{C}$. Cells were washed, fixed with $4 \%$ paraformaldehyde, and counterstained with a nucleic acid counterstain (DAPI for ARPE-19 or DRAQ5 for HUVEC, red fluorescence) prior to analysis. Cell surface binding was evaluated with secondary antibody alone (left column), bevacizumab (middle column) or aflibercept (right column) in the presence of $\mathrm{VEGF}_{121}(\mathbf{a}-\mathbf{c})$, $\operatorname{VEGF}_{165}(\mathbf{d}-\mathbf{f})$ or no ligand $(\mathbf{g}-$ i). Scale bar $=50 \mu \mathrm{m}$ in (a) and $100 \mu \mathrm{m}$ in (b)
A
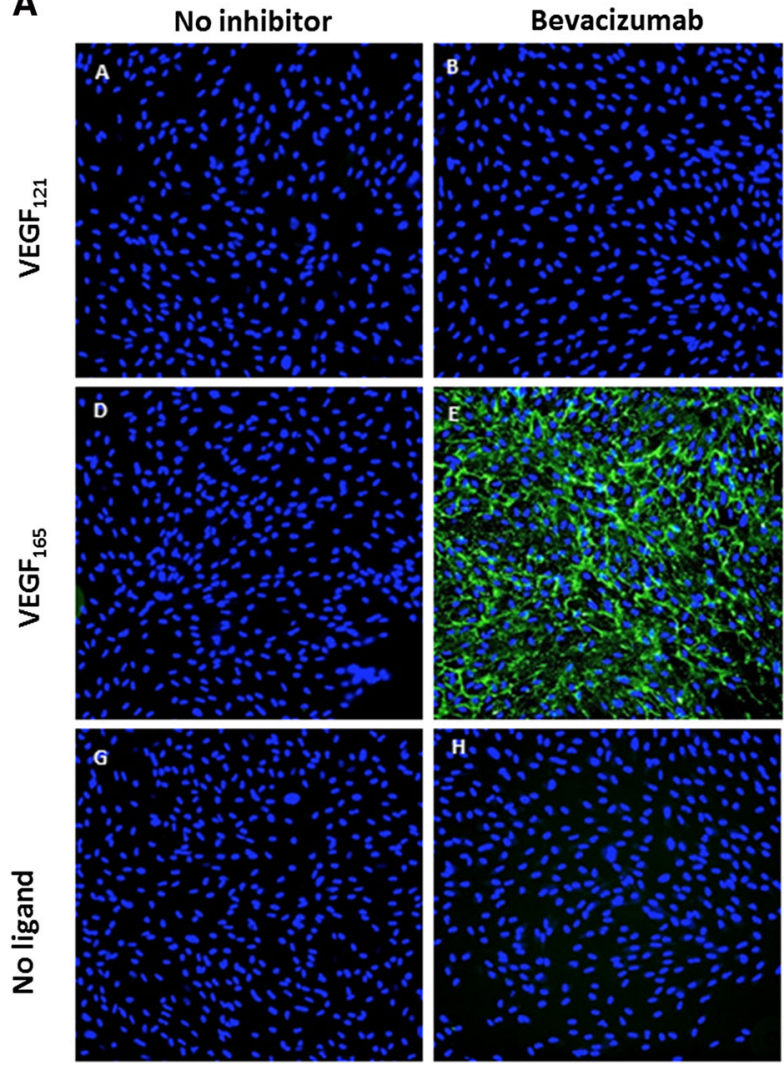

B
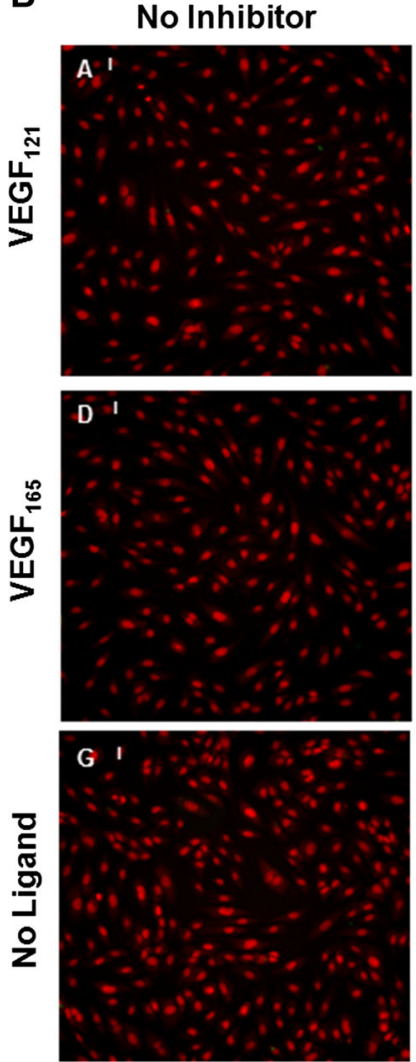

\section{Bevacizumab}
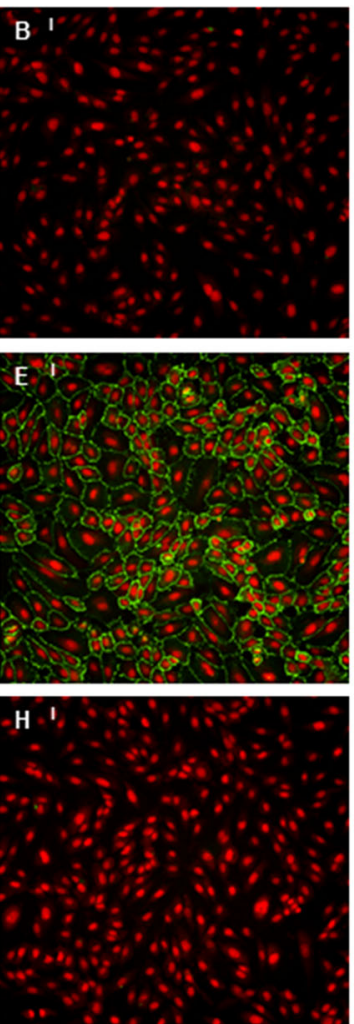

Aflibercept
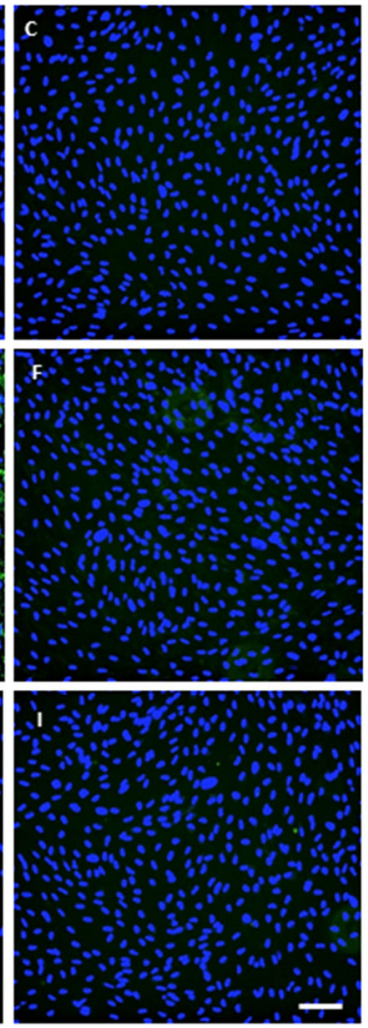

Aflibercept
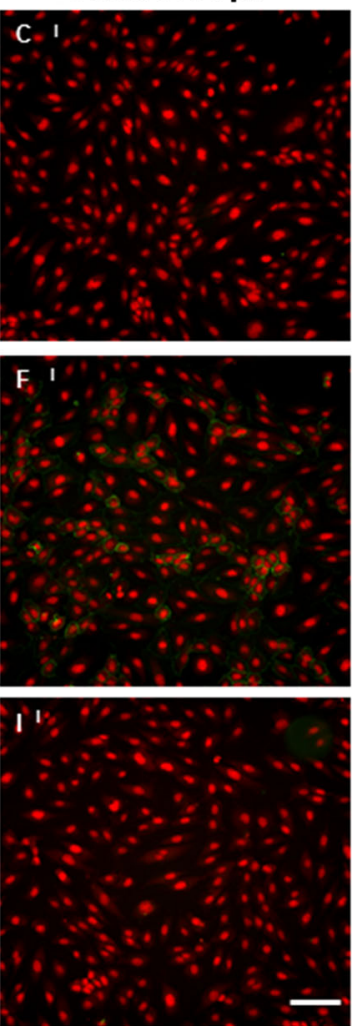
inhibitor:VEGF 165 complex mixtures (Figure S5 and Figure S6). Complexes binding to the cell surface of ARPE-19 were observed at bevacizumab: $\mathrm{VEGF}_{165}$ ratios between 0.06:1 and 4.5:1, with the greatest binding seen at a molar ratio of $0.1: 1$, and complex binding to HUVEC was observed at bevacizumab: $V_{E G F} 165$ ratios between $0.5: 1$ and 13.5:1, with maximal binding observed at a 1.5:1 molar ratio.

\section{Cell surface binding of bevacizumab:VEGF 165 complexes is dependent on heparin in ARPE-19 cells and neuropilin-1 in HUVEC}

Cell surface binding of bevacizumab: $\mathrm{VEGF}_{165}$ complexes was tested in the presence of heparin or recombinant human neuropilin-1 (rhNRP-1). Pre-binding of $\mathrm{VEGF}_{165}$ with soluble heparin concentrations of $250 \mathrm{nM}$ or higher prevented binding of bevacizumab: $\mathrm{VEGF}_{165}$ complexes to ARPE-19 cells (Fig. 5a). No significant blocking of bevacizumab: $V_{E G F} 165$ complex binding to ARPE-19 cells was observed with concentrations of rhNRP-1 of up to $100 \mathrm{nM}$ (Fig. 5a). In contrast, pre-binding of $\mathrm{VEGF}_{165}$ with rhNRP1 (25 nM or higher) prevented binding of bevacizumab:VEGF ${ }_{165}$ complexes to HUVEC (Fig. 5b), while no significant blocking of bevacizumab:VEGF 165 complex binding to HUVEC was observed in the presence of up to $1000 \mathrm{nM}$ soluble heparin (Fig. 5b). These results are consistent with surface plasmon resonance analysis of bevacizumab:VEGF 165 and aflibercept: $\mathrm{VEGF}_{165}$ in the presence of rhNRP-1 and heparin (Fig. 6a, b, S7A and B). Bevacizumab:VEGF $\mathrm{V}_{165}$ complexes were found to bind to both rhNRP-1- and heparin-coated surfaces at concentrations as low as $1 \mathrm{nM}$. Binding of aflibercept: $\mathrm{VEGF}_{165}$ complexes to rhNRP-1- and heparin-coated surfaces was only detected at complex concentrations of $100 \mathrm{nM}$ or greater.

\section{Cell surface binding is dependent on the concentration of endogenous VEGF $_{165}$}

ARPE-19 cells were used to test cell surface binding of bevacizumab and aflibercept in the presence of VEGF endogenously produced by these cells. ARPE-19 cells have been shown to express VEGF after several days in culture [31]. Cells in culture were incubated with aflibercept, bevacizumab, or hFc, for 3 days starting at day 2, 4, 9, and 14 , and surface binding was then examined 3 days later. Aflibercept and the $\mathrm{hFc}$ control showed minimal surface binding at all time points. In contrast, bevacizumab showed significant cell surface binding at the Day 9-12 and Day 14-17 time points (Fig. 7c-1 and 7d-1).

Next-generation sequencing and ELISA binding were used to determine the expression level and identity of the VEGF isoforms present in the culture medium at various time points. $\mathrm{VEGF}_{165}$ was found to be the predominant VEGF species present (Fig. 7m, n), with the concentration of this isoform increasing as a function of ARPE-19 time in culture. The highest concentrations of $\mathrm{VEGF}_{165}$ were found on the Day 9 and Day 28 time points, consistent with the high level of bevacizumab cell surface binding at later time points. These results closely resemble cell surface binding studies conducted with preformed bevacizumab:VEGF 165 complexes and suggest that bevacizumab can spontaneously form multimeric complexes in the presence of endogenous $\mathrm{VEGF}_{165}$.

\section{Discussion}

Several reports have indicated that bevacizumab, in contrast to ranibizumab, can bind cell surface-bound VEGF on RPE and endothelial cells [27, 32]. Additional studies have provided evidence that bevacizumab not only binds cellsurface-bound VEGF on RPE cells, but that this binding may trigger the complement cascade resulting in cell death $[3,33]$. Components of the complement pathway are known to play a role in AMD pathogenesis, although the mechanism has not been clearly defined. Activation of the complement cascade can result in damage to retinal cells as well as surrounding tissue [34], and conversely, complement components can contribute to neuronal homeostasis in the retina [35]. Aflibercept, like bevacizumab, contains an Fc domain; however, several reports have shown that this anti-VEGF agent does not induce changes in cell morphology, induce apoptosis, or decrease cell viability of retinal cells in culture [36, 37].

To further understand what could be driving these observed differences in vitro, we conducted a detailed analysis of bevacizumab and aflibercept when complexed with VEGF by analyzing their stoichiometry of binding, affinity to $\mathrm{Fc} \gamma$ receptors, propensity to activate platelets and ability to bind ARPE-19 and HUVEC. The results of these experiments demonstrate that in contrast to bevacizumab, which can form large multimeric complexes with VEGF, aflibercept forms a homogeneous 1:1 molar complex with VEGF and PlGF. The discrete monomeric complexes of aflibercept:VEGF do not allow avidity-driven $\mathrm{Fc}$ to $\mathrm{Fc} \gamma$ receptor interactions as seen with the large heterogeneous complexes that bevacizumab forms with VEGF when both are present at near equal molar ratios. Furthermore, since bevacizumab, unlike aflibercept, does not block heparin binding to $\mathrm{VEGF}_{165}$, these multimeric bevacizumab:VEGF complexes, in the presence of heparin, can activate Fc $\gamma$ RIIa receptors triggering platelet aggregation. Lastly, this fundamental difference in binding geometry explains the observations that no significant cell binding was observed for aflibercept:VEGF complexes, 
Fig. 5 Heparin and neuropilin1 differentially block bevacizumab cell surface binding. Surface binding to ARPE-19 (a) or HUVEC (b) cells was evaluated in the presence of soluble heparin and recombinant human neuropilin1. Cells pre-seeded onto collagen-coated 96-well plates were incubated at $37{ }^{\circ} \mathrm{C}$ for 30 min with serial dilutions of soluble heparin or rhNRP-1 precomplexed with $10 \mathrm{nM}$ VEGF $_{165}$. Bevacizumab was added to the cells to give a final concentration of $15 \mathrm{nM}$, followed by a 1-h incubation at $37^{\circ} \mathrm{C}$. Surface staining of bevacizumab was detected by incubation with A488 anti-hIgG (green fluorescence) at $4{ }^{\circ} \mathrm{C}$. Cells were washed, fixed with $4 \%$ paraformaldehyde, and incubated with a nucleic acid counterstain (DAPI for ARPE19 or DRAQ5 for HUVEC, red fluorescence) prior to analysis. Fluorescence was detected by Molecular Devices ImageXpress High-Content Screening System. Scale bar $=50 \mu \mathrm{m}$ in (a) and $100 \mu \mathrm{m}$ in $(\mathbf{b})$

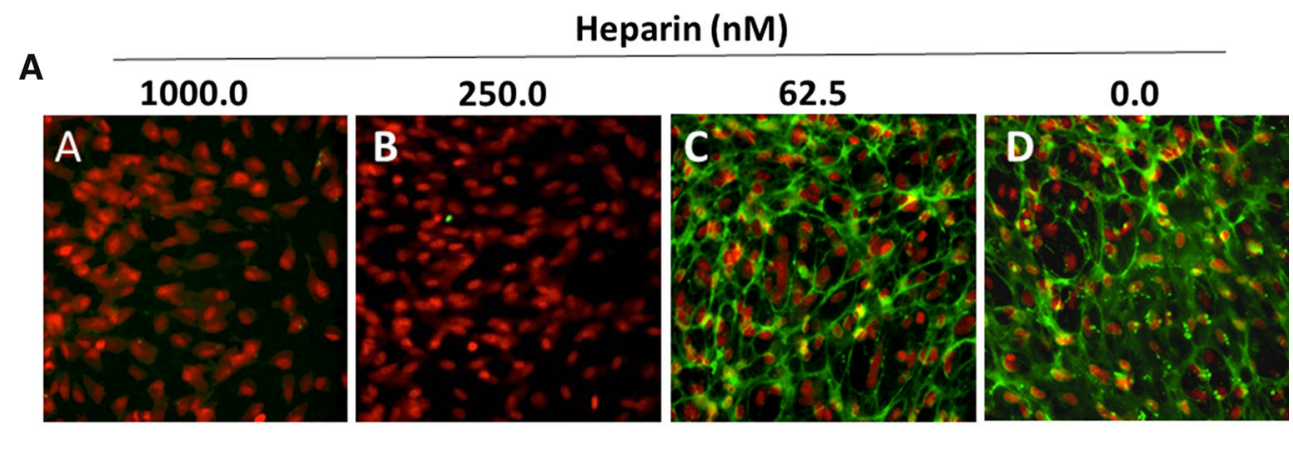

\section{Neuropilin-1 (nM)}

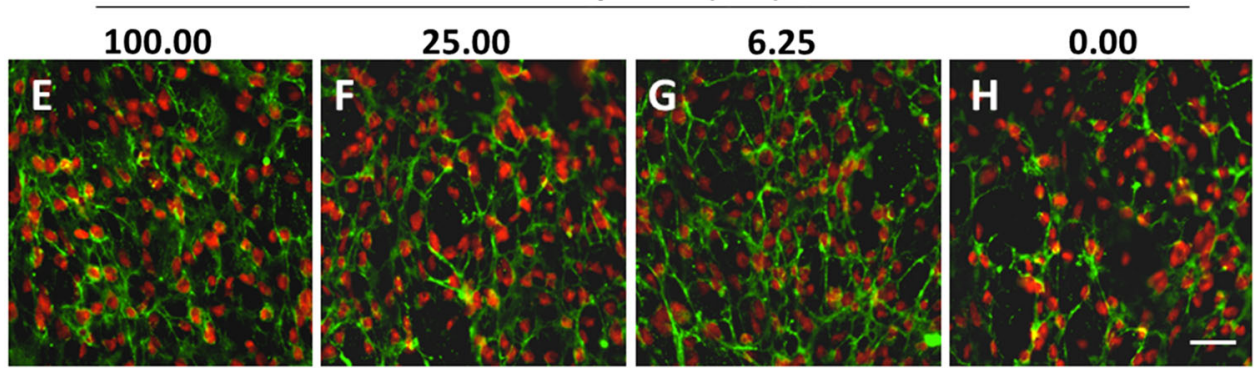

B

Heparin (nM)
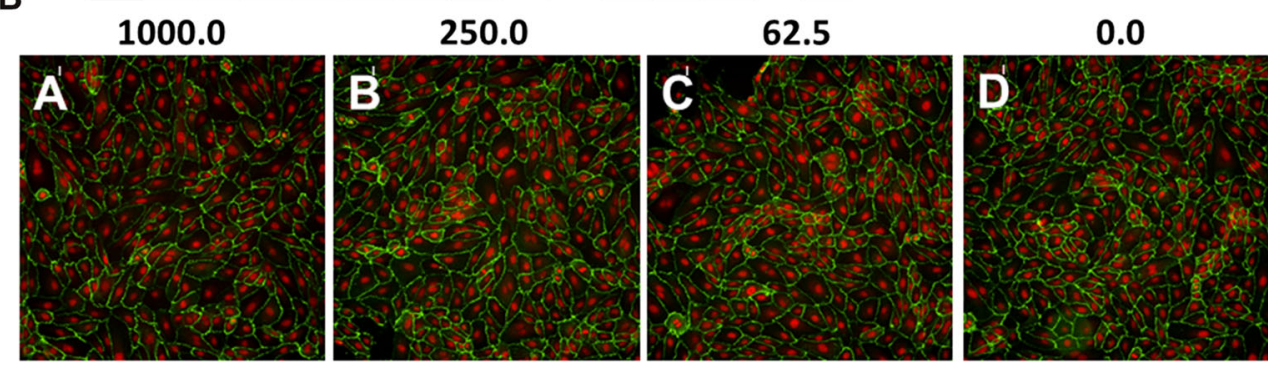

Neuropilin-1 (nM)
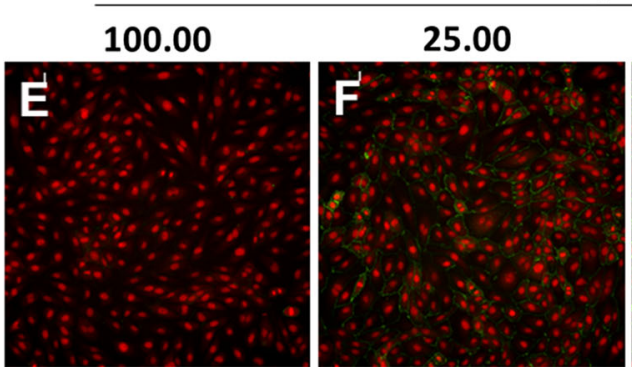

6.25
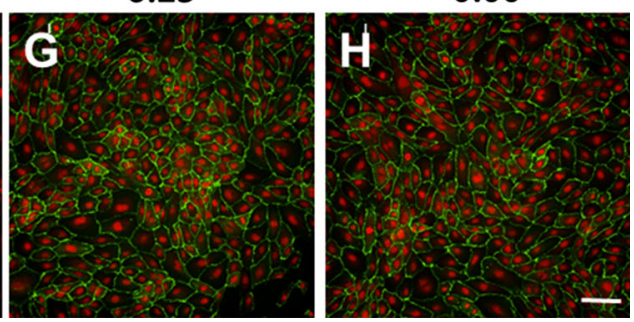

while the heterogeneous bevacizumab:VEGF complexes bound to the cell surfaces of both ARPE-19 and HUVEC.

This report demonstrates at molar ratios of 5:1 to 1:5, aflibercept to $\mathrm{VEGF}_{165}$, aflibercept was observed to form a 1:1 molar complex. In contrast, bevacizumab at the same molar ratios formed high molecular weight complexes with VEGF $_{165}$, in agreement with earlier published work [21]. When the affinity of these observed high molecular weight complexes to high- and low-affinity Fc $\gamma$ receptors was investigated, we demonstrated that bevacizumab, when bound to either $\mathrm{VEGF}_{121}$ or $\mathrm{VEGF}_{165}$ at equal molar ratios $(\sim 1 \mu \mathrm{M})$, had drastically increased $t_{1 / 2}$ values, ranging from $\sim$ threefold for the Fc $\gamma$ RI receptor to $\sim 177$-fold increase for the low-affinity Fc $\gamma \mathrm{RIIb}$ receptor, compared to bevacizumab alone. In contrast, aflibercept in complex with $\operatorname{VEGF}_{121}$ or $\operatorname{VEGF}_{165}$ at equal molar ratios $(\sim 1 \mu \mathrm{M})$ showed no appreciable difference in $t_{1 / 2}$ values relative to aflibercept alone.

Through platelet activation studies, we showed that when heparin was added to bevacizumab:VEGF complexes 
Fig. 6 In vitro binding of bevacizumab and aflibercept to NRP1.mFc and heparin-biotin by SPR (Biacore) in the presence of $\mathrm{VEGF}_{165}$. a Human NRP1.mFc (155 RU) was captured on an anti-mouse Fccoupled chip surface. The histogram represents bevacizumab and aflibercept at concentrations of 500,100,10, 5 , and $1 \mathrm{nM}$ either alone or precomplexed at 1:1 molar ratio with human $\mathrm{VEGF}_{121}$ or VEGF $_{165}$. b Heparin-biotin (35 RU) was captured on a neutravidin-coupled chip surface. The histogram represents bevacizumab and aflibercept at concentrations of $500,100,10,5$, and $1 \mathrm{nM}$ either alone or pre-complexed at 1:1 molar ratio with human VEGF $_{121}$ or $\mathrm{VEGF}_{165}$. Representative sensograms of bevacizumab and aflibercept binding to NRP1.mFc and heparin at $5 \mathrm{nM}$ are shown in Supplementary Figure 7
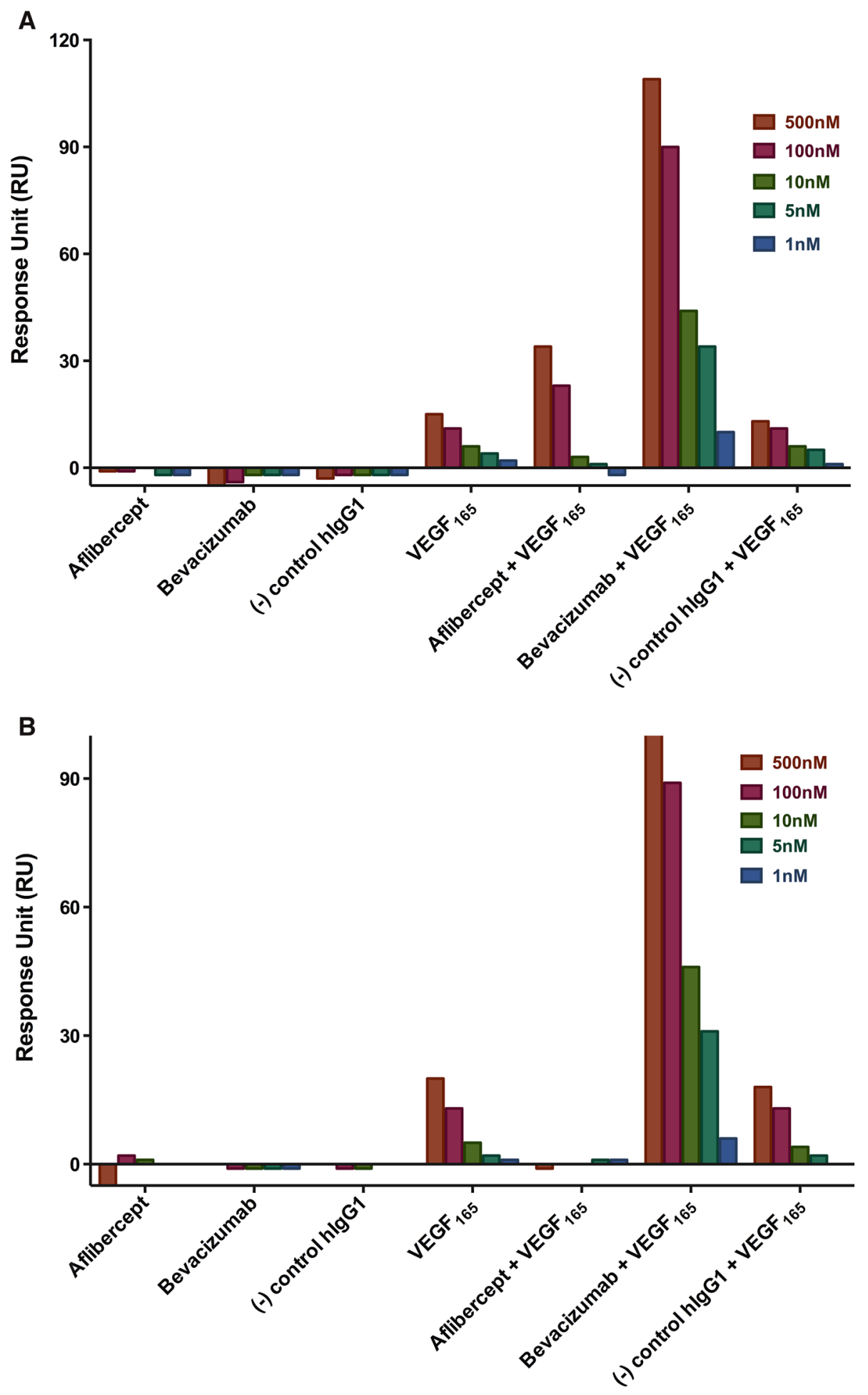

(100-400 nM), marked aggregation of platelets was observed. Heparin, in this context, allows for optimal Fc $\gamma$ RIIa receptor clustering by bringing the bevacizumab:VEGF complexes to the platelet surface [22]. However, when we increased the molar excess of bevacizumab ( $\geq$ fourfold relative to $\mathrm{VEGF}_{165}$ ), the ability to trigger platelet activation was lost, most likely due to the ability of excess bevacizumab to decrease the size of the multimeric complexes, reducing the avidity between bevacizumab's Fc domain and the Fc $\gamma$ RIIa receptor. In contrast, preformed complexes of aflibercept and $\mathrm{VEGF}_{165}$ at equal molar ratios in the presence of heparin failed to 


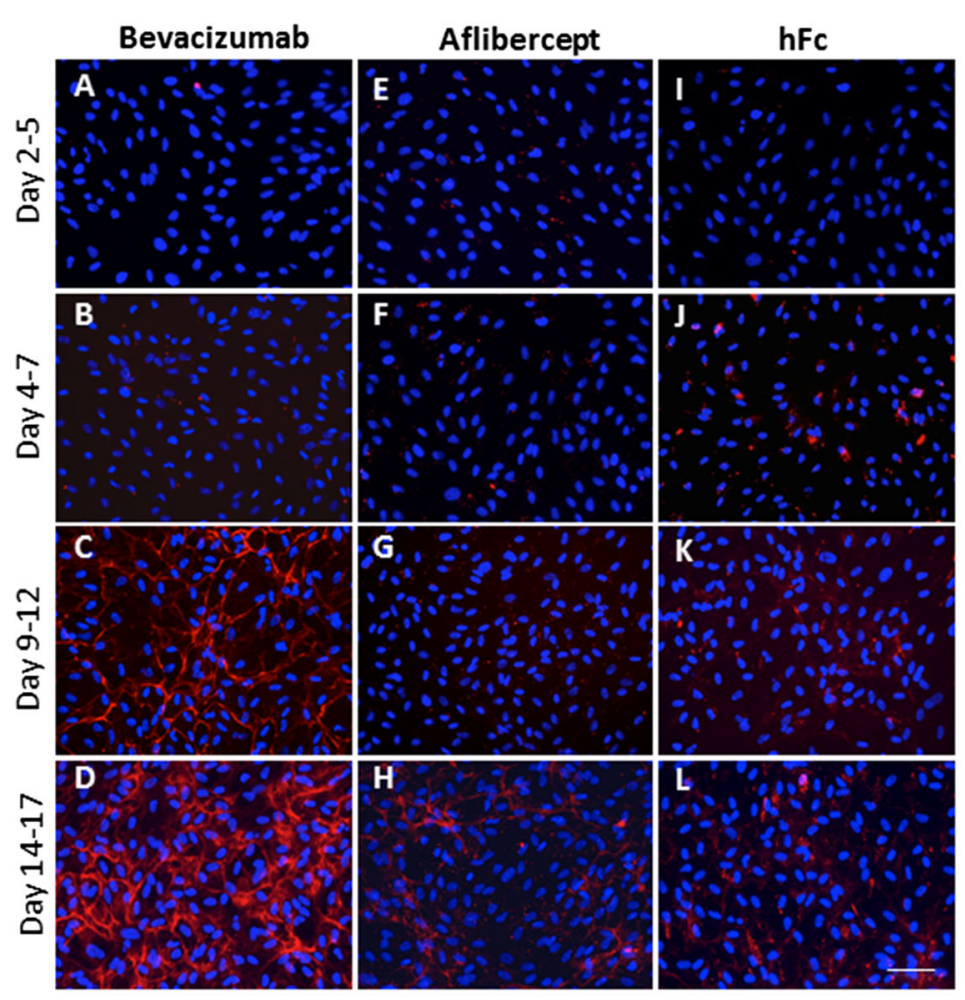

(M) ) Differential gene expression levels of hVEGF-A in cultured ARPE-19 cells by NextGeneration Sequencing (NGS)

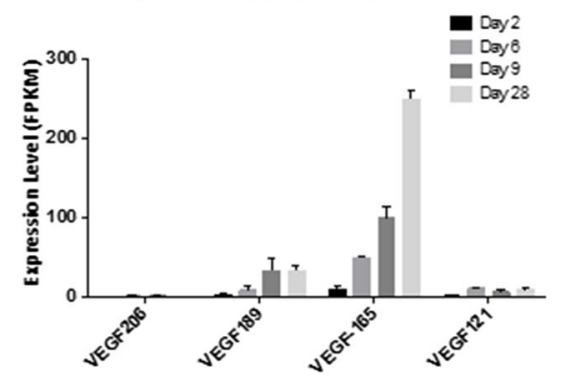

(N) hVEGF-A Level in culture medium (ELISA)

Fig. 7 Cell surface binding of bevacizumab is directly proportional to endogenous VEGF $_{165}$ concentration. ARPE-19 cells, cultured on human fibronectin-coated coverslips in six-well plates, were treated with equimolar concentration $(1.68 \mu \mathrm{M})$ of bevacizumab, aflibercept, or $\mathrm{hFc}$ for 3 days starting from different time points (Day 2, 4, 9, and 14) followed by immunofluorescence staining of cell surface-bound inhibitor (red fluorescence, detected with mouse antihuman IgG Fcspecific, and secondary Ab, goat anti-mouse IgG-Alexa flour 594.

induce aggregation of human platelets. Consistent with these results, serotonin release from platelets was not observed for aflibercept: $\mathrm{VEGF}_{165}$ complexes but was observed for bevacizumab:VEGF 165 complexes. These bevacizumab: VEGF $_{165}$ complexes could form when systemic or intravitreal levels of bevacizumab are low, approaching the concentrations of endogenous VEGF.

To study the potential sequelae of bevacizumab's immune complex formation with VEGF, we incubated bevacizumab:VEGF 165 with either ARPE-19 cells or HUVEC. At equimolar ratios of bevacizumab to $\mathrm{VEGF}_{165}$, the complexes bound to the ARPE-19 cell surface. Indeed, there was significant staining of the preformed bevacizumab:VEGF 165 complexes at molar ratios from 4.5:1 to $0.06: 1$. These findings support the earlier work of Klettner et al. [38] which showed that bevacizumab was taken up by primary porcine RPE cells as assessed by confocal laser scanning microscopy and flow cytometry. There was no staining on the cell surface with bevacizumab complexed with $\mathrm{VEGF}_{121}$, indicating that the heparin-binding domain
Nuclei were counterstained with DAPI in blue). Cells and culture media at various culture times (Days 2, 6, 9, and 28) were collected for next-generation sequencing and ELISA of VEGF expression levels. Cells treated with bevacizumab (a-d) showed an increased cell surface binding in confluent ARPE-19 cell culture, coincident with the upregulation of VEGF expression $(\mathbf{m}, \mathbf{n})$. Cells treated with aflibercept (e-h) or control protein $\mathrm{hFc}(\mathbf{i}-\mathbf{l})$ showed minimal binding at all time points. Scale Bar $=50 \mu \mathrm{m}$

and/or the NRP1-binding site was required for immune complex deposition. Very little cell surface staining was observed on either ARPE-19 cell or HUVEC by aflibercept:VEGF ${ }_{165}$ complex over a wide range of molar ratios.

The binding of bevacizumab on the cell surface only when in complex with $\mathrm{VEGF}_{165}$ but not $\mathrm{VEGF}_{121}$ points to the involvement of the positively charged heparin-binding domain found on $\mathrm{VEGF}_{165}$. The heparin-binding domain confers diverse functions on $\mathrm{VEGF}_{165}$ [39], including interaction with heparin and neuropilin present on the cell surface. Binding of the bevacizumab: $\mathrm{VEGF}_{165}$ complex to ARPE-19 cells was blocked by the addition of heparin but not neuropilin. Conversely, binding of the bevacizumab:VEGF 165 complex to HUVEC was blocked only by the addition of neuropilin, illustrating that both heparin or neuropilin can anchor these complexes to the cell surface.

To determine whether these immune complexes could form with endogenously produced VEGF, we added either bevacizumab or aflibercept to ARPE-19 cells after 
allowing VEGF production to proceed over various time periods (2, 4, 9, and 14 days). After quantifying VEGF levels using both ELISA and next-generation sequencing, it was clear that bevacizumab cell surface staining correlated with the levels of VEGF produced. As in the studies using exogenous VEGF, the addition of aflibercept to ARPE-19 cells containing different levels of VEGF did not result in detectable cell surface staining.

In conclusion, we have demonstrated that bevacizumab and aflibercept can exhibit strikingly different binding stoichiometries with VEGF. When the molar concentration of bevacizumab is within approximately tenfold that of VEGF, two molecules of bevacizumab can bind to each VEGF dimer via one of its two Fab arms, leaving the second Fab arm on each bevacizumab free to bind another VEGF dimer. This binding stoichiometry promotes the formation of large, multimeric complexes of bevacizumab which exhibit significantly enhanced binding affinity toward low-affinity Fc $\gamma$ receptors. Moreover, the heparinand neuropilin-binding sites of $\mathrm{VEGF}_{165}$ are not occluded when bound to bevacizumab, such that heparin/neuropilinmediated cell surface binding is also enhanced. That large multimeric complexes of bevacizumab:VEGF 165 exhibit enhanced binding to both heparin/neuropilin and lowaffinity Fc receptors on cell surfaces underlies the ability of these complexes to promote platelet aggregation and activation. In contrast, each aflibercept molecule forms a homogenous 1:1 complex with each VEGF dimer at all molar ratios of aflibercept:VEGF tested. This $1: 1$ binding stoichiometry does not enhance binding to heparin or neuropilin on cell surfaces. In addition, 1:1 aflibercept:VEGF complexes do not bind low-affinity $\mathrm{Fc} \gamma$ receptors more avidly than unbound aflibercept or monomeric IgG1, or cause platelet aggregation and activation. While there is no evidence to link the reported higher gastrointestinal disorders and the mechanism by which bevacizumab binds VEGF, we have shown that differences in binding at high molar ratios can be directly correlated to differences in $\mathrm{Fc} \gamma$ receptor binding, cell surface binding, and platelet activation.

\section{Materials and methods}

\section{Multi-angle laser light scattering detection coupled to size exclusion chromatography (SEC-MALLS)}

The SEC-MALLS system comprised an Agilent 1200 Series HPLC system equipped with an ultraviolet (UV) diode array detector coupled to a Wyatt Technology MiniDawn TREOS laser light scattering (LS) detector and an Optilab REX differential refractometer (RI) detector (Santa Barbara, CA). The detectors were connected in series in the following order: UV-LS-RI. LS and RI detectors were calibrated according to the instructions provided by Wyatt Technology.

Complexes comprising $20 \mu \mathrm{M}$ VEGF inhibitor (aflibercept [Regeneron] or bevacizumab [Roche]) and 100 $\mu \mathrm{M}$ VEGF $_{165}$ (Regeneron, produced in $\mathrm{CHO}$ cells) were prepared separately and incubated for $12 \mathrm{~h}$ at ambient temperature to form 1:5 molar ratio inhibitor:ligand complexes. Similarly, 5:1 inhibitor:ligand complexes were prepared with $100 \mu \mathrm{M}$ VEGF inhibitor and $20 \mu \mathrm{M}$ VEGF $_{165}$. Complexes comprising PlGF-2 (Regeneron) and VEGF inhibitor (aflibercept or bevacizumab) were prepared in the same manner as the inhibitor:VEGF 165 complexes. Appropriate amounts of unbound inhibitor $(20 \mu \mathrm{M})$ or ligand $(40 \mu \mathrm{M})$ were also injected separately into a preequilibrated Superose 12 10/300 GL (GE Healthcare) size exclusion column. The mobile phase was $10 \mathrm{mM}$ phosphate, $500 \mathrm{mM} \mathrm{NaCl}, \mathrm{pH} 7.0$ with a flow rate of $0.3 \mathrm{~mL} /$ min. Molar masses of free ligands, free inhibitor, and inhibitor:ligand complexes were determined using ASTRA software (Wyatt Technology) as previously described [40]. The standard deviation calculated from bovine serum albumin (BSA) standard samples was within $2 \%$ in different SEC-MALLS experiments.

\section{Surface plasmon resonance kinetic binding assay}

SPR experiments were performed on a Biacore 3000 instrument using a dextran-coated (CM4 or CM5) chip at $25{ }^{\circ} \mathrm{C}$. The running buffer was filtered HBS-T $(10 \mathrm{mM}$ Hepes, $150 \mathrm{mM} \mathrm{NaCl}, 3.4 \mathrm{mM}$ EDTA, $0.05 \%$ polysorbate 20, $\mathrm{pH}$ 7.4). A capture sensor surface was prepared by covalently immobilizing anti-histidine monoclonal antibody (His capture kit, GE Healthcare), anti-mouse Fc (Mouse antibody capture kit, GE Healthcare), or neutravidin (Thermo Fisher Scientific Inc.) to the chip surface using 1-Ethyl-3-[3-dimethylaminopropyl]carbodiimide hydrochloride/ $N$-hydroxysuccinimide (EDC/NHS) coupling chemistry. Following surface activation, capturing reagents in coupling buffer $(0.1 \mathrm{M}$ acetate buffer, $\mathrm{pH} 4.5)$ were injected over the activated chip surface until the binding signals in resonance unit (RU) reached about 3500 RU for the anti-histidine monoclonal antibody surface, $1500 \mathrm{RU}$ for the anti-mouse Fc polyclonal antibody, and 5000 RU for the neutravidin, respectively. The surfaces were then washed and treated with $10 \mathrm{mM}$ glycine$\mathrm{HCl}$ at $\mathrm{pH} 1.5$ to remove uncoupled residual proteins. The various his-tagged or myc-myc His-tagged Fc $\gamma$ receptor family members, mFc-tagged human NRP1 (Regeneron), and biotinylated heparin (Sigma-Aldrich) were injected over the corresponding capture surfaces to a low density at approximate $200 \mathrm{RU}$ in the running buffer with a concentration range between 5 and $10 \mu \mathrm{g} / \mathrm{mL}$. The His-tagged 
Fc $\gamma$ RIIA ${ }_{R 131}, \mathrm{Fc} \gamma \mathrm{RIIB} / \mathrm{C}, \mathrm{Fc} \gamma \mathrm{RIIIB}$, and Fc $\gamma \mathrm{RI}$ were purchased from R\&D Systems, and myc-myc His-tagged Fc $\gamma$ RIIIA $_{\mathrm{F} 176}$, and Fc $\gamma$ RIIIA $\mathrm{V}_{\mathrm{V} 176}$ were generated at Regeneron.

Following the capture step, bevacizumab (Roche) or aflibercept (Regeneron) solutions with and without equimolar concentrations of $\mathrm{VEGF}_{165}$ (Regeneron) or $\mathrm{VEGF}_{121}$ (R\&D Systems, produced in E. coli) (from $1.0 \mu \mathrm{M}$ to $31.25 \mathrm{nM}$ in a twofold serial dilutions) were individually injected over the various $\mathrm{Fc} \gamma$ receptor, human NRP1.mFc, and biotin-heparin surfaces, and the real-time binding signals were recorded. The specific binding sensorgrams were obtained using a double-referencing procedure as described by Myszka et al. [41] by subtracting the binding signal on the blank capture surface and sample buffer run. The binding data were then processed and analyzed using Scrubber software (version 2.0, BioLogic Software), and the dissociation rate constant $\left(k_{\mathrm{d}}\right)$ and dissociation half-life $t_{1 / 2}$ were calculated.

\section{Platelet aggregation}

\section{Washed platelet preparation}

Platelet concentrate was obtained from the NY Blood Center and used before expiration. Washed platelet suspensions were prepared from pooled platelets obtained from citrated phosphate dextrose blood using the method of Cazenave et al. [42]. Approximately $20 \mathrm{~mL}$ of platelet concentrate was centrifuged $(2200 \mathrm{~g}$, $25{ }^{\circ} \mathrm{C}$ ) for $12 \mathrm{~min}$. The supernatant was removed, and $20 \mathrm{~mL}$ of modified Tyrode's buffer $(137 \mathrm{mM} \mathrm{NaCl}$, $2.7 \mathrm{mM} \mathrm{KCl}, 12 \mathrm{mM} \mathrm{NaHCO} 3,0.42 \mathrm{mM} \mathrm{NaH} \mathrm{PO}_{4}$, $2 \mathrm{mM} \mathrm{MgCl}_{2}, 5 \mathrm{mM}$ HEPES, $5.55 \mathrm{mM}$ dextrose, $\mathrm{pH}$ 6.2) containing $1.5 \mathrm{U} / \mathrm{mL}$ apyrase Grade VII (Sigma-Aldrich) and $0.5 \mu \mathrm{M}$ prostacyclin $I_{2}$ (Cayman Chemical) was added. The platelets were resuspended and allowed to rest for $10 \mathrm{~min}$ at $37{ }^{\circ} \mathrm{C}$. Following this, another $0.5 \mu \mathrm{M}$ of prostacyclin $I_{2}$ was added, and the platelets were centrifuged $\left(1900 \mathrm{~g}, 25^{\circ} \mathrm{C}\right)$ for $8 \mathrm{~min}$. The supernatant was removed, and another $20 \mathrm{~mL}$ of modified Tyrode's buffer containing $1.5 \mathrm{U} / \mathrm{mL}$ apyrase Grade VII and $0.5 \mu \mathrm{M}$ prostacyclin $I_{2}$ was used to resuspend the platelets. The platelets were allowed to rest for $10 \mathrm{~min}$ at $37{ }^{\circ} \mathrm{C}$. After this second wash step, $0.5 \mu \mathrm{M}$ of prostacyclin was added and the platelets were centrifuged $\left(1900 \mathrm{~g}, 25^{\circ} \mathrm{C}\right)$ for $8 \mathrm{~min}$. The supernatant was removed, and $40 \mathrm{~mL}$ of Tyrode's buffer containing calcium (Tyrode's buffer with $2 \mathrm{mM} \mathrm{CaCl}_{2}, \mathrm{pH}$ 7.35) was added. The platelets were resuspended and diluted to 300,000 cells/ $\mu \mathrm{L}$ using the same buffer. Using this procedure, the washed platelet suspension was stable for $4 \mathrm{~h}$ when stored at $37{ }^{\circ} \mathrm{C}$.

\section{Platelet aggregometry}

Platelet aggregation was monitored at an absorbance of $600 \mathrm{~nm}$ using a Beckman DU7400 spectrophotometer fitted with a homemade thermostatic stirring chamber. In typical experiments, $1.8 \mathrm{~mL}$ of platelets was added to 3-mL plastic cuvettes containing a stir bar designed for spectrophotometer cells (Fisher Scientific). The platelets, under constant stirring, were allowed to reach thermoequilibrium for $5 \mathrm{~min}$. Then, $100 \mu \mathrm{L}$ of PBS containing agonist (epinephrine, Sigma-Aldrich) and unfractionated heparin (Sigma-Aldrich) was added. After $1 \mathrm{~min}$, data collection was begun and an additional $100 \mu \mathrm{L}$ of PBS containing the bevacizumab:VEGF or aflibercept:VEGF complex was added. Platelet aggregation was typically monitored for 10-15 min. Plots of percent aggregation were calculated by taking the initial average absorbance of the platelets $(\sim 1.3-1.4 \mathrm{AU})$ as $0 \%$ aggregation and an absorbance of zero as $100 \%$ aggregation.

\section{Serotonin release assay}

In vitro platelet activation was studied using a serotonin release model described by Meyer et al. [22]. Human platelets were loaded with ${ }^{14} \mathrm{C}$-serotonin (PerkinElmer), then washed, and incubated at $22{ }^{\circ} \mathrm{C}$ with the test complex for $1 \mathrm{~h}$ under constant stirring. Released serotonin was counted in the supernatant and expressed as a percentage of the total serotonin loaded into the platelets. To create bevacizumab:VEGF 165 or aflibercept:VEGF 165 complexes, VEGF $_{165}$ (R\&D Systems) and bevacizumab (Roche) or aflibercept (Regeneron) were coincubated in PBS at equimolar concentrations $(2.5 \mu \mathrm{M})$ for $15 \mathrm{~min}$ at $22{ }^{\circ} \mathrm{C}$. The complex was then added to ${ }^{14} \mathrm{C}$-serotonin-loaded platelets in the presence of heparin (Sigma-Aldrich). Complex was added to platelets to obtain a final concentration of $0.1,0.2,0.5$, or $1 \mu \mathrm{M}$ and tested in the presence of a range of unfractionated heparin concentrations $(0.5$ $500 \mu \mathrm{g} / \mathrm{mL}$ ).

\section{Assessment of platelet-activating activity in Fc $\gamma$ RIIa transgenic mice}

\section{Experimental animals}

B6;SJL-Tg (Fc $\gamma$ RIIa)11Mkz (FCGR2A) mice were obtained from Jackson Laboratories and bred in the Animal Care Facility at Florida Hospital, Orlando, in compliance with approved Institutional Animal Care and Use Committee (IACUC) guidelines and protocols. All experiments were performed in 8- to 15 -week-old mice weighing between 16 and $20 \mathrm{~g}$. All animals were genotyped and confirmed positive for the Fc $\gamma$ RIIa transgene according to 
Jackson Laboratories PCR Protocols. Some animals were injected with PBS (vehicle containing no immune complex components) in order to establish baseline platelet counts, as described below.

\section{Mouse blood sampling, platelet counting, and intravenous injection procedures}

For IV injections, mice were immobilized in a standard restrainer and warmed using a heat lamp for 2 min to dilate the tail vein. Immune complexes were preassembled by mixing antibody + antigen at a $1: 1$ molar ratio $(126 \mu \mathrm{g}$ M90 [Florida Hospital] + $45 \mu \mathrm{g}$ CD154 [Peprotech], or $35 \mu \mathrm{g}$ VEGF [Peprotech, produced in E. coli] + either $126 \mu \mathrm{g}$ bevacizumab [Genentech] or $92 \mu \mathrm{g}$ aflibercept [Regeneron] \pm heparin [Sigma-Aldrich] in PBS). Immune complexes were injected slowly in a $200-\mu \mathrm{L}$ bolus into the lateral tail vein. Animals were then removed from their restraining device and placed in an open observation cage for monitoring. Ten minutes after reagent injection, mice were anesthetized by isoflurane inhalation. Approximately $500 \mu \mathrm{L}$ of blood was collected by cardiac puncture via 27 -gauge needles into syringes containing $50 \mu \mathrm{L}$ of acid citrate dextrose (ACD). The blood was immediately placed in a polypropylene collection tube containing $50 \mu \mathrm{L}$ of ACD, and platelet counts were measured using an automated cell counter. Platelet counts were adjusted for citrate solution volume. All animals were observed for signs of distress throughout the test procedure, specifically for rapid shallow breathing, hunched posture, and signs of decreased or dysfunctional locomotor activity. The combination of these symptoms is often referred to as a "shock" or "thrombotic" phenotype. The observation of such symptoms was recorded along with platelet counts per animal. Together, platelet counts and signs of physical distress constitute the primary data in this animal model.

\section{Histochemical analysis of lung sections}

Following blood draws, animals were killed by $\mathrm{CO}_{2}$ inhalation. Mouse lungs were dissected en bloc from isofluorane-anesthetized animals not subjected to cardiac puncture. Lungs were rinsed in PBS and immediately placed in $10 \%$ formalin-PBS for at least $24 \mathrm{~h}$ prior to paraffin embedding. Histopathology laboratory technicians cut some distance into the paraffin block (lung tissue) prior to initial sectioning. Cut sections $(2 \mu \mathrm{m}$ thick) were deparaffinized and rehydrated and then processed by an automated H\&E staining process at the Florida Hospital main Histopathology Laboratory. Lungs sections from each group were analyzed microscopically for evidence of thrombosis by two independent observers. Also, reference lungs were harvested from baseline animals and processed identically as described above. Fields were captured from each section using a Nikon Eclipse 80i upright microscope equipped with Plan Fluor objectives $(10 \times, N A=0.3$, DIC; $20 \times, N A=0.5$, DIC; $40 \times, N A=0.75$, DIC; and $60 \times$, $N A=0.85$, not DIC), a DC-Fi1 digital camera, and a DSL2 image capture device. The eyepiece and camera had a collective magnification of $10 \times$, resulting in final image magnifications of $100,200,400$, or $600 \times$, respectively, with each objective lens. The capture device was activated by pressing a "Capture" button. The image capture device was set by integrated software to automatically adjust for white balance. Observers were instructed to adjust lamp intensity and stage diaphragm (aperture) settings as needed per image; thus, variations in brightness, contrast, and color hue may be observed in some images. Images were converted from TIF format to JPEG and processed in Adobe Photoshop Elements (v8) without region-specific modifcations (i.e., all changes were global, and no regionspecific change was made to any image).

\section{Statistical analysis}

Statistical analysis was performed using SigmaPlot v11 software. The distributions of experimental data sets for mouse platelet counts were determined by normal probability analysis. All groups were found to be normally distributed and of equal variance. Therefore, differences between groups were analyzed by one-way ANOVA using the raw data (rather than the means and standard deviations). The statistical test used was the multiple comparisons versus control group Bonferroni $t$ test (alpha $=0.050: 1.000)$.

\section{Cell surface binding of VEGF inhibitors to ARPE-19 cells in the presence of exogenous VEGF}

Confluent ARPE-19 cells (ATCC) on 96-well collagencoated plates (Greiner CellCoat) were incubated with $5 \mathrm{nM}$ bevacizumab (Roche), or aflibercept (Regeneron) alone or in the presence of $10 \mathrm{nM} \mathrm{VEGF}_{165}$ (Regeneron) or $10 \mathrm{nM}$ $\mathrm{VEGF}_{121}$ (R\&D Systems) at $37^{\circ} \mathrm{C}$ for $1 \mathrm{~h}$. Cell surfacebound VEGF inhibitors were detected with Alexa 488 goat antihuman $\operatorname{IgG}(\mathrm{H}+\mathrm{L})$ Fab fragment (A488-anti-hIgG, Jackson Immunoresearch), followed by fixation with $4 \%$ paraformaldehyde and counterstaining with DAPI. Fluorescence was detected using a Molecular Devices ImageXpress Micro XL High-Content Imaging System equipped with a Nikon $10 \times$ Plan Fluor WD objective lens (NA 0.30). All images were acquired with a Molecular Devices 1.4 megapixel cooled CCD camera using MetaXepress ${ }^{\circledR}$ High-Content Image Acquisition and Analysis Software and analyzed using PerkinElmer Columbus Image Data Storage and Analysis System. 
Figures were made in Adobe Photoshop. No adjustments were made to the original images.

\section{Cell surface binding of VEGF inhibitors to HUVEC in the presence of exogenous VEGF}

HUVEC (Vec Technologies) were seeded into 96-well collagen-coated plates (Greiner CellCoat) at a concentration of 20,000 cells/well in complete medium (Vec Technologies) and incubated overnight at $37{ }^{\circ} \mathrm{C}$. The cells were washed $2 \times$ in PBS, followed by sequential addition of $10 \mathrm{nM}$ VEGF $_{165}$ or $10 \mathrm{nM} \mathrm{VEGF}_{121}$ and serial dilutions of bevacizumab or aflibercept in assay medium (2\% FBS in PBS). Control wells containing ligand, bevacizumab, or aflibercept alone were also evaluated. After a 2-h incubation at $37{ }^{\circ} \mathrm{C}$, the cells were washed $2 \times$ in PBS. The presence of cell-bound inhibitor was determined by incubation with $1 \mu \mathrm{g} / \mathrm{mL}$ A488-anti-hIgG (Jackson) in assay medium for $30 \mathrm{~min}$ at $4{ }^{\circ} \mathrm{C}$. The cells were washed $2 \times$ in PBS and then fixed in $3.7 \%$ formaldehyde in PBS for $20 \mathrm{~min}$ at room temperature followed by a final wash with PBS. Cells were counterstained with Draq5 (Cell Signaling Technologies) following the manufacturer's instructions and imaged using Molecular Devices ImagExpress Micro XL High-Content Imaging System equipped with a Nikon 20X S Plan Fluor EL WD objective lens (NA 0.45; WD 8.2-6.9 mm). All images were acquired with a Molecular Devices 1.4 megapixel cooled CCD camera using MetaXepress ${ }^{\circledR}$ High-Content Image Acquisition and Analysis Software and analyzed using PerkinElmer Columbus Image Data Storage and Analysis System. Figures were made in Adobe Photoshop. No adjustments were made to the original images.

\section{Heparin or neuropilin-1 blockade of VEGF $_{165}$ bridging in ARPE-19 cells}

ARPE-19 cells (ATCC) were incubated for 30 min with serial dilutions of soluble heparin (Sigma-Aldrich; starting from $1000 \mathrm{nM}, 1: 2$ ) or rhNRP-1-mFc (Regeneron; starting from $100 \mathrm{nM}, 1: 2)$ pre-incubated with $10 \mathrm{nM}$ VEGF $_{165}$ (Regeneron). Bevacizumab was added to the cells (final concentration $10 \mathrm{nM}$ ), followed by a 1-h incubation at $37^{\circ} \mathrm{C}$. Surface staining of bevacizumab was detected with A488-anti-hIgG (Jackson Immunoresearch), followed by fixation in $4 \%$ paraformaldehyde and counterstaining with DAPI. Fluorescence was detected by a Molecular Devices ImageXpress Micro XL High-Content Imaging System equipped with a Nikon 20x Plan Fluor ELWD objective lens (NA 0.45; WD 8.2-6.9 mm). All images were acquired with a Molecular Devices 1.4 megapixel cooled CCD camera using MetaXepress ${ }^{\circledR}$ High-Content Image Acquisition and Analysis Software and analyzed using
PerkinElmer Columbus Image Data Storage and Analysis System. Figures were made in Adobe Photoshop. No adjustments were made to the original images.

\section{Heparin or neuropilin-1 blockade of VEGF 165 bridging in HUVEC}

Serial dilutions of heparin (Sigma-Aldrich) or rhNRP-1$\mathrm{mFc}$ (Regeneron) were premixed with $10 \mathrm{nM} \mathrm{VEGF}_{165}$. The mixture was then added to HUVEC plated as described above and incubated for $30 \mathrm{~min}$ at $37{ }^{\circ} \mathrm{C}$. A constant concentration of $15 \mathrm{nM}$ bevacizumab was then added to cells, followed by a 1 -h incubation at $37^{\circ} \mathrm{C}$. The cells were washed, detected with $1 \mu \mathrm{g} / \mathrm{mL}$ A488anti-hIgG (Jackson), counterstained with Draq5 (Cell Signaling Technologies), and imaged using Molecular Devices ImagExpress Micro XL High-Content Imaging System equipped with a Nikon 20x S Plan Fluor EL WD objective lens (NA 0.45; WD $8.2-6.9 \mathrm{~mm}$ ). All images were acquired with a Molecular Devices 1.4 megapixel cooled CCD camera using MetaXepress $^{\circledR}$ High-Content Image Acquisition and Analysis Software and analyzed using PerkinElmer Columbus Image Data Storage and Analysis System. Figures were made in Adobe Photoshop. No adjustments were made to the original images.

\section{Cell surface binding of VEGF inhibitors to APRE-19 cells in the presence of endogenous VEGF}

ARPE-19 cells (ATCC), cultured on human fibronectin (Corning)-coated coverslips in six-well plates, were treated with equimolar concentration $(1.68 \mu \mathrm{M})$ of bevacizumab (Roche), aflibercept (Regeneron), or hFc (Regeneron) for 3 days starting from different time points (Days 2, 4, 9, and 14) followed by immunofluorescence staining of cell surface-bound inhibitor [red fluorescence, detected with mouse antihuman IgG Fc-specific, and secondary Ab, goat anti-mouse $\operatorname{IgG}(\mathrm{h}+\mathrm{L})$-Alexa Fluor 594 (Life Technologies)]. Nuclei were counterstained with DAPI in blue. Fluorescence was detected in ProLong ${ }^{\circledR}$ Gold antifade reagent (Life Technologies) using a Nikon Eclipse 80i microscope equipped with a Nikon Plan APO 20x objective lens (NA 0.75). All images were acquired with a Diagnostic Instruments Spot Camera using Diagnostic Instruments Spot 4.7 software and analyzed using PerkinElmer Columbus Image Data Storage and Analysis System. Figures were made in Adobe Photoshop. The photomerge function was used to merge blue and red channel images.

Cells and culture media at various culture times (Days 2, 6,9 , and 28) were collected for next-generation sequencing (Illumina Hiseq 2000) and ELISA (R\&D Systems) of VEGF expression levels. 
Acknowledgments The authors thank Katrina Fracchiolla for assistance in preparing the manuscript and figures. We also thank our research associates for their assistance in the conduct of these studies, and our colleagues at Regeneron, Sanofi, and Bayer HealthCare for their critical reading of this manuscript, and many helpful comments and suggestions.

Open Access This article is distributed under the terms of the Creative Commons Attribution 4.0 International License (http://crea tivecommons.org/licenses/by/4.0/), which permits unrestricted use, distribution, and reproduction in any medium, provided you give appropriate credit to the original author(s) and the source, provide a link to the Creative Commons license, and indicate if changes were made.

\section{References}

1. Gerber HP, Hillan KJ, Ryan AM, Kowalski J, Keller GA, Rangell L, Wright BD, Radtke F, Aguet M, Ferrara N (1999) VEGF is required for growth and survival in neonatal mice. Development 126(6):1149-1159

2. Grothey A, Galanis E (2009) Targeting angiogenesis: progress with anti-VEGF treatment with large molecules. Nat Rev Clin Oncol 6(9):507-518. doi:10.1038/nrclinonc.2009.110

3. Hauser S, Weich HA (1993) A heparin-binding form of placenta growth factor (PIGF-2) is expressed in human umbilical vein endothelial cells and in placenta. Growth Factors 9(4):259-268

4. Bressler SB (2009) Introduction: understanding the role of angiogenesis and antiangiogenic agents in age-related macular degeneration. Ophthalmology 116(10 Suppl):S1-S7. doi:10. 1016/j.ophtha.2009.06.045

5. Bressler NM (2004) Age-related macular degeneration is the leading cause of blindness. JAMA 291(15):1900-1901

6. Kliffen M, Sharma HS, Mooy CM, Kerkvliet S, de Jong PT (1997) Increased expression of angiogenic growth factors in agerelated maculopathy. Br J Ophthalmol 81(2):154-162

7. Wells JA, Murthy R, Chibber R, Nunn A, Molinatti PA, Kohner EM, Gregor ZJ (1996) Levels of vascular endothelial growth factor are elevated in the vitreous of patients with subretinal neovascularisation. Br J Ophthalmol 80(4):363-366

8. Funatsu H, Yamashita H, Noma H, Mimura T, Yamashita T, Hori S (2002) Increased levels of vascular endothelial growth factor and interleukin- 6 in the aqueous humor of diabetics with macular edema. Am J Ophthalmol 133(1):70-77. doi:10.1016/S00029394(01)01269-7

9. Moradi A, Sepah YJ, Sadiq MA, Nasir H, Kherani S, Sophie R, Do DV, Nguyen QD (2013) Vascular endothelial growth factor trap-eye (Aflibercept) for the management of diabetic macular edema. World J Diabetes 4(6):303-309. doi:10.4239/wjd.v4.i6. 303

10. Krispel C, Rodrigues M, Xin X, Sodhi A (2013) Ranibizumab in diabetic macular edema. World J Diabetes 4(6):310-318. doi:10. 4239/wjd.v4.i6.310

11. Gragoudas ES, Adamis AP, Cunningham ET Jr, Feinsod M, Guyer DR (2004) Pegaptanib for neovascular age-related macular degeneration. N Engl J Med 351(27):2805-2816. doi:10.1056/ NEJMoa042760

12. Rosenfeld PJ, Brown DM, Heier JS, Boyer DS, Kaiser PK, Chung CY, Kim RY (2006) Ranibizumab for neovascular age-related macular degeneration. N Engl J Med 355(14):1419-1431. doi:10. 1056/NEJMoa054481

13. Hurwitz H, Fehrenbacher L, Novotny W, Cartwright T, Hainsworth J, Heim W, Berlin J, Baron A, Griffing S, Holmgren E,
Ferrara N, Fyfe G, Rogers B, Ross R, Kabbinavar F (2004) Bevacizumab plus irinotecan, fluorouracil, and leucovorin for metastatic colorectal cancer. N Engl J Med 350(23):2335-2342. doi:10.1056/NEJMoa032691

14. Avery RL, Pieramici DJ, Rabena MD, Castellarin AA, Nasir MA, Giust MJ (2006) Intravitreal bevacizumab (Avastin) for neovascular age-related macular degeneration. Ophthalmology 113(3):363-372. doi:10.1016/j.ophtha.2005.11.019

15. Martin DF, Maguire MG, Ying GS, Grunwald JE, Fine SL, Jaffe GJ (2011) Ranibizumab and bevacizumab for neovascular agerelated macular degeneration. N Engl J Med 364(20):1897-1908. doi:10.1056/NEJMoa1102673

16. Chakravarthy U, Harding SP, Rogers CA, Downes SM, Lotery AJ, Culliford LA, Reeves BC (2013) Alternative treatments to inhibit VEGF in age-related choroidal neovascularisation: 2-year findings of the IVAN randomised controlled trial. Lancet 382(9900):1258-1267. doi:10.1016/S0140-6736(13)61501-9

17. Krebs I, Schmetterer L, Boltz A, Told R, Vecsei-Marlovits V, Egger S, Schonherr U, Haas A, Ansari-Shahrezaei S, Binder S (2013) A randomised double-masked trial comparing the visual outcome after treatment with ranibizumab or bevacizumab in patients with neovascular age-related macular degeneration. $\mathrm{Br} \mathrm{J}$ Ophthalmol 97(3):266-271. doi:10.1136/bjophthalmol-2012-302391

18. Moja L, Lucenteforte E, Kwag KH, Bertele V, Campomori A, Chakravarthy U, D'Amico R, Dickersin K, Kodjikian L, Lindsley K, Loke Y, Maguire M, Martin DF, Mugelli A, Muhlbauer B, Puntmann I, Reeves B, Rogers C, Schmucker C, Subramanian ML, Virgili G (2014) Systemic safety of bevacizumab versus ranibizumab for neovascular age-related macular degeneration. Cochrane Database Syst Rev 9:CD011230. doi:10.1002/ 14651858.CD011230.pub2

19. Diabetic Retinopathy Clinical Research N, Wells JA, Glassman AR, Ayala AR, Jampol LM, Aiello LP, Antoszyk AN, ArnoldBush B, Baker CW, Bressler NM, Browning DJ, Elman MJ, Ferris FL, Friedman SM, Melia M, Pieramici DJ, Sun JK, Beck RW (2015) Aflibercept, bevacizumab, or ranibizumab for diabetic macular edema. N Engl J Med 372(13):1193-1203. doi:10. 1056/NEJMoa1414264

20. Ferrara N, Damico L, Shams N, Lowman H, Kim R (2006) Development of ranibizumab, an anti-vascular endothelial growth factor antigen binding fragment, as therapy for neovascular agerelated macular degeneration. Retina 26(8):859-870. doi:10. 1097/01.iae.0000242842.14624.e7

21. Rudge JS, Holash J, Hylton D, Russell M, Jiang S, Leidich R, Papadopoulos N, Pyles EA, Torri A, Wiegand SJ, Thurston G, Stahl N, Yancopoulos GD (2007) VEGF Trap complex formation measures production rates of VEGF, providing a biomarker for predicting efficacious angiogenic blockade. Proc Natl Acad Sci USA 104(47):18363-18370. doi:10.1073/pnas.0708865104

22. Meyer T, Robles-Carrillo L, Robson T, Langer F, Desai H, Davila M, Amaya M, Francis JL, Amirkhosravi A (2009) Bevacizumab immune complexes activate platelets and induce thrombosis in FCGR2A transgenic mice. J Thromb Haemost 7(1):171-181. doi:10.1111/j.1538-7836.2008.03212.x

23. Presta LG, Chen H, O'Connor SJ, Chisholm V, Meng YG, Krummen L, Winkler M, Ferrara N (1997) Humanization of an anti-vascular endothelial growth factor monoclonal antibody for the therapy of solid tumors and other disorders. Cancer Res 57(20):4593-4599

24. Chen Y, Wiesmann C, Fuh G, Li B, Christinger HW, McKay P, de Vos AM, Lowman HB (1999) Selection and analysis of an optimized anti-VEGF antibody: crystal structure of an affinitymatured $\mathrm{Fab}$ in complex with antigen. $\mathrm{J}$ Mol Biol 293(4):865-881. doi:10.1006/jmbi.1999.3192

25. Papadopoulos N, Martin J, Ruan Q, Rafique A, Rosconi MP, Shi E, Pyles EA, Yancopoulos GD, Stahl N, Wiegand SJ (2012) 
Binding and neutralization of vascular endothelial growth factor (VEGF) and related ligands by VEGF Trap, ranibizumab and bevacizumab. Angiogenesis 15(2):171-185. doi:10.1007/s10456011-9249-6

26. Stoop JW, Zegers BJ, Sander PC, Ballieux RE (1969) Serum immunoglobulin levels in healthy children and adults. Clin Exp Immunol 4(1):101-112

27. Klettner AK, Kruse ML, Meyer T, Wesch D, Kabelitz D, Roider J (2009) Different properties of VEGF-antagonists: bevacizumab but not Ranibizumab accumulates in RPE cells. Graefes Arch Clin Exp Ophthalmol 247(12):1601-1608. doi:10.1007/s00417009-1136-0

28. Holash J, Davis S, Papadopoulos N, Croll SD, Ho L, Russell M, Boland P, Leidich R, Hylton D, Burova E, Ioffe E, Huang T, Radziejewski C, Bailey K, Fandl JP, Daly T, Wiegand SJ, Yancopoulos GD, Rudge JS (2002) VEGF-Trap: a VEGF blocker with potent antitumor effects. Proc Natl Acad Sci USA 99(17):11393-11398. doi:10.1073/pnas.172398299

29. Schmidt-Erfurth U, Kaiser PK, Korobelnik JF, Brown DM, Chong V, Nguyen QD, Ho AC, Ogura Y, Simader C, Jaffe GJ, Slakter JS, Yancopoulos GD, Stahl N, Vitti R, Berliner AJ, Soo Y, Anderesi M, Sowade O, Zeitz O, Norenberg C, Sandbrink R, Heier JS (2014) intravitreal aflibercept injection for neovascular age-related macular degeneration: ninety-six-week results of the VIEW studies. Ophthalmology 121(1):193-201. doi:10.1016/j. ophtha.2013.08.011

30. Bruhns P, Iannascoli B, England P, Mancardi DA, Fernandez N, Jorieux S, Daeron M (2009) Specificity and affinity of human Fcgamma receptors and their polymorphic variants for human IgG subclasses. Blood 113(16):3716-3725. doi:10.1182/blood2008-09-179754

31. Ma W, Lee SE, Guo J, Qu W, Hudson BI, Schmidt AM, Barile GR (2007) RAGE ligand upregulation of VEGF secretion in ARPE-19 cells. Invest Ophthalmol Vis Sci 48(3):1355-1361. doi:10.1167/iovs.06-0738

32. Heiduschka P, Fietz H, Hofmeister S, Schultheiss S, Mack AF, Peters S, Ziemssen F, Niggemann B, Julien S, Bartz-Schmidt KU, Schraermeyer U, Tubingen Bevacizumab Study G (2007) Penetration of bevacizumab through the retina after intravitreal injection in the monkey. Invest Ophthalmol Vis Sci 48(6):2814-2823. doi:10.1167/iovs.06-1171

33. Zeng Q, Schaal S, Kaplan HJ, Tezel HJ (2010) Ability to bind Fcreceptors on retinal pigment epithelium (RPE) can explain the higher occurence of RPE tears with bevacizumab (Avastin ${ }^{\circledR}$ ) compared with ranibizumab (Lucentis ${ }^{\circledR}$ ). Invest Ophthalmol Vis Sci 51(13):4954

34. Anderson DH, Radeke MJ, Gallo NB, Chapin EA, Johnson PT, Curletti CR, Hancox LS, Hu J, Ebright JN, Malek G, Hauser MA Rickman CB, Bok D, Hageman GS, Johnson LV (2010) The pivotal role of the complement system in aging and age-related macular degeneration: hypothesis re-visited. Prog Retin Eye Res 29(2):95-112

35. Benoit ME, Tenner AJ (2011) Complement protein C1q-mediated neuroprotection is correlated with regulation of neuronal gene and microRNA expression. J Neurosci 31(9):3459-3469

36. Schnichels S, Hagemann U, Januschowski K, Hofmann J, BartzSchmidt KU, Szurman P, Spitzer MS, Aisenbrey S (2013) Comparative toxicity and proliferation testing of aflibercept, bevacizumab and ranibizumab on different ocular cells. Br J Ophthalmol 97(7):917-923. doi:10.1136/bjophthalmol-2013303130

37. Klettner A, Recber M, Roider J (2014) Comparison of the efficacy of aflibercept, ranibizumab, and bevacizumab in an RPE/choroid organ culture. Graefes Arch Clin Exp Ophthalmol 252(10):1593-1598. doi:10.1007/s00417-014-2719-y

38. Klettner AK, Kruse ML, Meyer T, Wesch D, Kabelitz D, Roider J (2009) Different properties of VEGF-antagonists: bevacizumab but not ranibizumab accumulates in RPE cells. Graefes Arch Clin Exp Ophthalmol 247:1601-1608

39. Parker MW, Xu P, Li X, Vander Kooi CW (2012) Structural basis for selective vascular endothelial growth factor-A (VEGF-A) binding to neuropilin-1. J Biol Chem 287(14):11082-11089. doi:10.1074/jbc.M111.331140

40. Wen J, Arakawa T, Philo JS (1996) Size-exclusion chromatography with on-line light-scattering, absorbance, and refractive index detectors for studying proteins and their interactions. Anal Biochem 240(2):155-166. doi:10.1006/abio.1996.0345

41. Myszka DG (1999) Improving biosensor analysis. J Mol Recognit 12(5):279-284. doi:10.1002/(SICI)1099-1352(199909/10)12: 5<279:AID-JMR473>3.0.CO;2-3

42. Cazenave JP, Hemmendinger S, Beretz A, Sutter-Bay A, Launay J (1983) Platelet aggregation: a tool for clinical investigation and pharmacological study. Methodology. Ann Biol Clin (Paris) 41(3):167-179 